\title{
The Binary Bi-Rh Phase Diagram: Stable and Metastable Phases
}

\author{
Peter Kainzbauer $^{1} \cdot$ Klaus W. Richter $^{1} \cdot{\text { Herbert } \text { Ipser }^{1}}^{1}$
}

Submitted: 11 August 2017/in revised form: 14 September 2017/Published online: 13 October 2017

(C) The Author(s) 2017. This article is an open access publication

\begin{abstract}
The binary bismuth-rhodium (Bi-Rh) phase diagram was reinvestigated from 23 to 60 at. $\% \mathrm{Rh}$ with focus on the BiRh phase, applying powder-X-ray diffraction (XRD), high temperature powder-XRD, differential thermal analyses and scanning electron microscopy. The phase boundaries of the $\mathrm{BiRh}$ phase at $750{ }^{\circ} \mathrm{C}$ and the temperature of its peritectic decomposition were refined. In addition, the existence of the two phases $\mathrm{Bi}_{4} \mathrm{Rh}$ and $\mathrm{Bi}_{2} \mathrm{Rh}$ (in two modifications depending on temperature) could be confirmed. Most of the reaction temperatures reported in the literature could be verified within a range of about $\pm 10{ }^{\circ} \mathrm{C}$. Nevertheless, a few temperatures had to be revised, such as those of the peritectic reactions $\mathrm{L}+\mathrm{Rh} \rightleftharpoons \mathrm{BiRh}$ at $979{ }^{\circ} \mathrm{C}$ and $\mathrm{L}+\mathrm{BiRh} \rightleftharpoons \beta-\mathrm{Bi}_{2} \mathrm{Rh}$ at $785^{\circ} \mathrm{C}$. No evidence could be found for the presence of a stable $\mathrm{Bi}_{3} \mathrm{Rh}$ phase in well annealed samples; from the present results it must be concluded that $\mathrm{Bi}_{3} \mathrm{Rh}$ is actually metastable. On the other hand, a new orthorhombic phase $\mathrm{BiRh}_{0.81}$ was discovered which crystallizes in the $\mathrm{MnP}$ structure type (Pmna). It was found that the temperatures of the transition between the low-temperature modification $\alpha$ $\mathrm{Bi}_{2} \mathrm{Rh}$ and its high-temperature form $\beta-\mathrm{Bi}_{2} \mathrm{Rh}$ depend considerably on the presence or absence of metastable $\mathrm{Bi}_{3} \mathrm{Rh}$ and stable $\mathrm{BiRh}_{0.81}$, respectively.
\end{abstract}

The original version of this article was revised due to a retrospective Open Access order.

Herbert Ipser

Herbert.Ipser@univie.ac.at

1 University of Vienna, Faculty of Chemistry, Department of Inorganic Chemistry - Functional Materials, Althanstrasse 14, 1090 Vienna, Austria
Keywords Bi-Rh system $\cdot \mathrm{BiRh}_{0.81}$ phase $\cdot$ differential thermal analysis $\cdot$ phase diagram $\cdot$ scanning electron microscopy $\cdot$ x-ray diffraction

\section{Introduction}

The intermetallic phase $\alpha$-BiMn with the NiAs-type structure has been suggested as an interesting ferromagnetic material in the past with the major advantage of not containing rare earth elements. ${ }^{[1]}$ Unfortunately, it has not been possible to synthesize this phase as single-phase bulk material despite several decades of intensive research (see e.g. Ref 2-6). A possible approach to circumvent the synthesis difficulties was considered the addition of a third component such as $\mathrm{Ni}, \mathrm{Pt}$ or $\mathrm{Rh}$, which form intermetallic phases with Bi that are iso-typic to $\alpha$-BiMn. ${ }^{[7-9]}$

Stabilization of BiMn by Rh was described by Lee et al. ${ }^{[10]}$, however, it was the non ferromagnetic hightemperature modification $\beta$-BiMn that was stabilized down to lower temperatures. A ferromagnetic ternary compound $\mathrm{Bi}_{4} \mathrm{Mn}_{5} \mathrm{Rh}_{2}$ was identified by Street et al. ${ }^{[11]}$ though with a Curie temperature of $-7^{\circ} \mathrm{C}$. A similar observation was made more recently by Taufour et al. ${ }^{[12]}$ who described a ferromagnetic compound $\mathrm{BiMn}_{1.05} \mathrm{Rh}_{0.02}$ with a Curie temperature of $143{ }^{\circ} \mathrm{C}$.

On the other hand, Suits ${ }^{[13]}$ discovered ferromagnetism in Bi-substituted $\mathrm{MnRh}$ with the composition $\mathrm{Mn}_{0.8} \mathrm{Bi}_{0.2-}$ $\mathrm{Rh}$. Based on these observations, a systematic study of the ternary Bi-Mn-Rh system was considered of interest, with the possibility of finding additional intermetallic phases, which might possibly exhibit ferromagnetism. During this study it was found that the binary Bi-Rh phase diagram was still not fully known, in particular, nothing was known about the accurate homogeneity range of the NiAs-type 
phase BiRh. This triggered a new and thorough investigation of the binary Bi-Rh phase diagram.

In the course of this study it became apparent that some of the phases reported in literature are metastable (as already suspected by other authors), with their appearance depending on the conditions of synthesis and heat treatment. On the other hand, an additional, previously unknown, phase was discovered after extended annealing.

\section{Literature Review}

The first investigations of $\mathrm{Bi}-\mathrm{Rh}$ alloys date back to Rössler ${ }^{[14]}\left(\mathrm{Bi}_{4} \mathrm{Rh}\right)$ and Wöhler and $\mathrm{Metz}^{[15]}\left(\mathrm{Bi}_{2} \mathrm{Rh}\right)$, and a first phase diagram was presented by Rode. ${ }^{[16]}$ In a series of papers, several Russian research groups (see Ref 17-22 e.g.) studied Bi-Rh alloys with a special focus on superconducting properties. A more refined version of the phase diagram was reported by Kuz'min et al. ${ }^{[21,22]}$ as well as Ross and Hume-Rothery. ${ }^{[9,23]}$ Based on the existing data, Predel $^{[24]}$ assessed the Bi-Rh system. The most recent study of the phase relationships in the Bi-rich part of the Bi-Rh system is from Weitzer et al., ${ }^{[25]}$ which was included in the most recent assessment of the system by Okamoto. ${ }^{[26]}$

There are several discrepancies between the published phase diagrams in Ref 24 and 26 especially with regard to the peritectic melting temperatures of $\beta-\mathrm{Bi}_{2} \mathrm{Rh}$ and $\mathrm{BiRh}$, the homogeneity range of $\mathrm{BiRh}$, the existence of a $\mathrm{Bi}_{3} \mathrm{Rh}$ phase, and the transition temperature from $\alpha-\mathrm{Bi}_{2} \mathrm{Rh}$ into its high-temperature form $\beta-\mathrm{Bi}_{2} \mathrm{Rh}$ (see Table 1 ).
The intermetallic phase BiRh has been known to crystallize in the hexagonal $\mathrm{NiAs}\left(\mathrm{B} 8_{1}\right)$ type structure with space group $\mathrm{P6}_{3} / \mathrm{mmc}^{\text {[9] }}$ This structure type is characterized by atoms of a main group element $\mathrm{B}(\mathrm{Bi})$, forming a hexagonal close-packed lattice on Wyckoff position $2 c$ (1/ $3,2 / 3,1 / 4)$ with the octahedral sites being occupied by transition metal atoms $\mathrm{T}(\mathrm{Rh})$ on Wyckoff position $2 a(0,0$, $0)$. In general, the stoichiometry of the NiAs-type phases may vary from $\mathrm{TB}_{2}$ to $\mathrm{T}_{2} \mathrm{~B}$, including the ideal composition of TB. A striking feature of NiAs phases is their tendency to form broad homogeneity ranges at high temperatures. The orthorhombic MnP (B31) type structure is closely related to the hexagonal NiAs-type. The MnP structure (see section 4.5 $\mathrm{BiRh}_{0.81}$ ) is a slightly distorted form of the NiAs structure with both $\mathrm{B}$ and $\mathrm{T}$ atoms on Wyckoff position $4 c(x, 1 / 4, z)$. (An extensive overview on the properties of NiAs and MnP phases was given by Kjekshus and Pearson ${ }^{[27]}$ ).

The compound $\mathrm{Bi}_{2} \mathrm{Rh}$ exists in two modifications, the monoclinic $\alpha$ modification, which is stable at room temperature, and the triclinic high-temperature $\beta$ modification. In early studies ${ }^{[18,19,28]}$ the authors described $\alpha-\mathrm{Bi}_{2} \mathrm{Rh}$ as a rhombic phase and interpreted a thermal effect at $498^{\circ} \mathrm{C}$ as a polymorphic transformation of $\mathrm{Bi}_{2} \mathrm{Rh}$. This transition temperature was originally estimated by Rode ${ }^{[16]}$ but could not be confirmed by Ross and Hume-Rothery. The latter authors found the transition temperature by high-temperature $\mathrm{X}$-ray diffraction (XRD) at about $430{ }^{\circ} \mathrm{C}^{[23]}$ and corrected the temperature in a later publication to $425^{\circ} \mathrm{C}$. ${ }^{[9]}$ These values are in good agreement with thermal arrest
Table 1 Invariant reactions in the Bi-Rh system

\begin{tabular}{|c|c|c|c|c|c|c|}
\hline \multirow{2}{*}{$\frac{\text { Reaction }}{\mathrm{L}+\mathrm{Rh} \rightleftharpoons \mathrm{BiRh}}$} & \multicolumn{3}{|c|}{ Composition, at.\% Rh } & \multirow{2}{*}{$\frac{T,{ }^{\circ} \mathrm{C}}{977}$} & \multirow{2}{*}{$\begin{array}{l}\text { Reaction type } \\
\text { Peritectic }\end{array}$} & \multirow{2}{*}{$\frac{\text { Ref. }}{24}$} \\
\hline & 46 & 100 & 50 & & & \\
\hline & 45 & 100 & $<48$ & 997 & & 26 \\
\hline & 47 & 100 & 50 & $979 \pm 2$ & & p.w. \\
\hline \multirow[t]{3}{*}{$\mathrm{L}+\mathrm{BiRh} \rightleftharpoons \beta-\mathrm{Bi}_{2} \mathrm{Rh}$} & 29.5 & 48 & 33.3 & 780 & Peritectic & 24 \\
\hline & 29.5 & 45 & 33.3 & 776 & & 26 \\
\hline & 29.0 & 47 & 33.3 & $785 \pm 2$ & & p.w. \\
\hline \multirow[t]{3}{*}{$\mathrm{L}+\beta-\mathrm{Bi}_{2} \mathrm{Rh} \rightleftharpoons \mathrm{Bi}_{4} \mathrm{Rh}$} & 7.0 & 33.3 & 20 & 460 & Peritectic & 24 \\
\hline & 8.3 & 33.3 & 20 & 466 & & 26 \\
\hline & & & & $459 \pm 2$ & & p.w. \\
\hline \multirow[t]{2}{*}{$\beta-\mathrm{Bi}_{2} \mathrm{Rh} \rightleftharpoons \alpha-\mathrm{Bi}_{2} \mathrm{Rh}$} & $\ldots$ & 33.3 & $\ldots$ & 425 & Transition & 24,29 \\
\hline & $\ldots$ & 33.3 & $\ldots$ & 370 & & 26 \\
\hline$\beta-\mathbf{B i}_{2} \mathbf{R h}+\mathbf{B i R h}_{\mathbf{0 . 8 1}} \rightleftharpoons \alpha-\mathbf{B i}_{2} \mathbf{R h}$ & $<33.3$ & 45 & $>33.3$ & $\sim 438$ & Peritectoid & p.w. \\
\hline$\beta-B i_{2} R h+B i R h \rightleftharpoons \alpha-B i_{2} R h$ & $<33.3$ & 45 & $>33.3$ & $448 \pm 2$ & & \\
\hline$\beta-\mathbf{B} \mathbf{i}_{2} \mathbf{R h} \rightleftharpoons \mathbf{B i}_{4} \mathbf{R h}+\alpha-\mathbf{B} \mathbf{i}_{2} \mathbf{R h}$ & $<33.3$ & 20 & $>\mathbf{3 3 . 3}$ & $426 \pm 3$ & Eutectoid & \\
\hline \multirow[t]{2}{*}{$\mathrm{L} \rightleftharpoons \mathrm{Bi}+\mathrm{Bi}_{4} \mathrm{Rh}$} & 1.0 & 0.0 & 20 & 269 & Eutectic & 24 \\
\hline & 0.5 & 0.0 & 20 & 266 & & 26 \\
\hline$\alpha-\mathrm{Bi}_{2} \mathrm{Rh}+\mathrm{Bi}_{4} \mathrm{Rh} \rightleftharpoons \mathrm{Bi}_{3} \mathrm{Rh}(\mathrm{a})$ & 33.3 & 20 & 25 & 433 & Peritectoid(b) & 26 \\
\hline $\mathrm{Bi}_{3} \mathrm{Rh} \rightleftharpoons \alpha-\mathrm{Bi}_{2} \mathrm{Rh}+\mathrm{Bi}_{4} \mathrm{Rh}(\mathrm{a})$ & 25 & 33.3 & 20 & 336 & Eutectoid(b) & 26 \\
\hline
\end{tabular}

Italics: estimated concentration values; p.w. (bold letters and numbers): present work, if the metastable $\mathrm{Bi}_{3} \mathrm{Rh}$ phase is not present; (a) metastable reactions; (b) reaction not confirmed in this study 
measurements by Kuz'min et al. who obtained $420^{[21]}$ and $430{ }^{\circ} \mathrm{C} .{ }^{[22]}$ Kjekshus and Rakke ${ }^{[29]}$ determined the first order transition temperature by DTA analysis and quenching experiments as $425 \pm 3{ }^{\circ} \mathrm{C}$, Fjellvag and Furuseth $^{[30]}$ as $427 \pm 10{ }^{\circ} \mathrm{C}$. Weitzer et al. ${ }^{[25]}$ found the XRD patterns of the $\alpha$ - and $\beta$-modification of $\mathrm{Bi}_{2} \mathrm{Rh}$ in samples quenched below and above $370{ }^{\circ} \mathrm{C}$, respectively.

Early investigations could not provide single crystals of $\beta-\mathrm{Bi}_{2} \mathrm{Rh}$ of sufficient quality in order to solve the crystal structure. Ruck ${ }^{[31]}$ synthesized $\beta-\mathrm{Bi}_{2} \mathrm{Rh}$ crystals by using the subhalide method and found that the triclinic $\beta$-phase crystallizes in its own structure type. He pointed out that twinning of $\beta-\mathrm{Bi}_{2} \mathrm{Rh}$ simulates a pseudo-monoclinic cell that is, within error limits, compatible with the structure data of Kuz'min and Zhuravlev. ${ }^{[21]}$ In addition, he concluded that the existence of a monoclinic high temperature $\gamma$-modification, emerging from a second order phase transformation, could not be excluded.

The existence of the phase $\mathrm{Bi}_{3} \mathrm{Rh}$, which was described in Ref 20, 28, 30, 32, and 33 but not detected by Ross and Hume-Rothery, ${ }^{[9]}$ was confirmed by Weitzer et al. ${ }^{[25]}$ These authors described the phase between $433{ }^{\circ} \mathrm{C}$ (formed by a peritectoid reaction $\beta-\mathrm{Bi}_{2} \mathrm{Rh}+\mathrm{Bi}_{4} \mathrm{Rh} \rightleftharpoons \mathrm{Bi}_{3} \mathrm{Rh}$ ) and $336{ }^{\circ} \mathrm{C}$ (eutectoid decomposition into $\alpha-\mathrm{Bi}_{2} \mathrm{Rh}$ and $\mathrm{Bi}_{4} \mathrm{Rh}$ ). Quite contrary, Fjellvag and Furuseth ${ }^{[30]}$ had reported a transformation of $\mathrm{Bi}_{3} \mathrm{Rh}$, apparently stable at room temperature, into a two-phase mixture of $\alpha-\mathrm{Bi}_{2} \mathrm{Rh}$ and $\mathrm{Bi}_{4} \mathrm{Rh}$ on heating above $172 \pm 10^{\circ} \mathrm{C}$.

Apart from these phases, a metastable compound $\mathrm{Bi}_{14}$ $\mathrm{Rh}_{3}$ was reported by $\mathrm{Gu}$ et al. ${ }^{[34]}$ It is in metastable equilibrium with the liquid phase and decomposes into $\mathrm{Bi}_{4} \mathrm{Rh}$ and $\mathrm{Bi}$ at $247{ }^{\circ} \mathrm{C}$ according to Weitzer et al. ${ }^{[25]}$

Contrary to the Bi-rich part of the $\mathrm{Bi}-\mathrm{Rh}$ phase diagram, the composition range with $x_{\mathrm{Rh}}>0.4$ is much less extensively investigated. Okamoto ${ }^{[26]}$ gave the stability field of $\mathrm{BiRh}$ between 45 and $<48$ at.\% $\mathrm{Rh}$, independent of temperature. These values were based on data by Glagoleva and Zhdanov ${ }^{[17]}$ who determined the lattice parameters of $\mathrm{BiRh}$ as a function of concentration. They annealed the samples at $800{ }^{\circ} \mathrm{C}$, however, they did not quench them but rather cooled them slowly down to room temperature. They found $\mathrm{BiRh}$ existing between 44.7 and 47.5 at.\% Rh, which indicates a homogeneity range on the $\mathrm{Bi}$ rich side of the stoichiometric composition. On the other hand, Ross and Hume-Rothery ${ }^{[9]}$ reported the phase field between 48 and 50.6 at.\% Rh based on samples that had been annealed at $780{ }^{\circ} \mathrm{C}$. The same authors measured also the temperature dependence of the lattice parameters for a sample $\mathrm{Rh}_{50} \mathrm{Bi}_{50}$ between room temperature and about $975{ }^{\circ} \mathrm{C}$.

A comparison of crystallographic data available from the literature and data obtained in this study is presented in Table 2 .

\section{Experimental Section}

\subsection{Sample Preparation}

Base material for all samples were pure element pieces of Bi $(99.999 \%$, ASARCO, New Jersey, USA, manually pulverized, grain size $<0.09 \mathrm{~mm})$ and $\mathrm{Rh}$ powder $(99.95 \%$ ÖGUSSA, Austria). Calculated amounts of the powders were mixed and pressed to pellets in a $5 \mathrm{~mm}$ pressing cylinder under a load of 20-25 kN. Pellets of samples containing more than 52.5 at.\% Rh were melted in an arc furnace (Bühler MAM) on a water-cooled copper plate under Ar of $99.999 \%$ purity ( 0.5 bar) using $\mathrm{Zr}$ as getter material and sealed into evacuated silica glass tubes ( 10 $0^{-3}$ mbar). All other pellets were sealed into evacuated silica glass tubes and melted over an oxyhydrogen flame under shaking, with optical control of the melting process. All samples (total amount 250-1000 mg), were annealed at different temperatures for at least 2 weeks and quenched in cold water. All annealing processes were carried out in muffle furnaces (Nabertherm, Germany) with a temperature accuracy of approximately $\pm 5^{\circ} \mathrm{C}$.

All alloy compositions given in the Tables are nominal compositions. Independent of the synthesis method, a loss of $<2$ wt. $\%$ could be determined by re-weighing the quenched samples.

\subsection{Characterization}

Phase identification was performed at ambient conditions by powder-XRD on a Bruker D8 Advance Diffractometer in Bragg-Brentano pseudo-focusing geometry (reflection setting), using $\mathrm{Cu}-\mathrm{K} \alpha$ radiation and a LynxEye ${ }^{\circledR}$ one-dimensional silicon strip detector (exposure time: $2 \mathrm{~h}$ ). Two selected samples with 35 and 50 at.\% Rh were analyzed by high temperature powder-XRD. The measurement was performed under vacuum, using an Anton Paar XRK 900 reactor chamber on a Bruker D8 Advance Diffractometer. For evaluation and Rietveld refinement of all diffraction patterns the TOPAS ${ }^{\circledR} 4.2$ software $^{[35]}$ was used.

Samples (except one with 43.5 at.\% Rh) containing between 42.5 and 52.5 at.\% Rh and annealed at $750{ }^{\circ} \mathrm{C}$ were investigated by electron microprobe analysis (EMPA) with a Cameca SX 100 using wavelength dispersive X-ray spectroscopy (WDX) at $20 \mathrm{kV}$. The instrument was calibrated with $\mathrm{Bi}$ and $\mathrm{Rh}$ standard material. All other samples were investigated using a scanning electron microscope (Zeiss Supra $55 \mathrm{VP}$ ) with energy-dispersive x-ray spectroscopy (EDX). Backscattered electrons were used for surface visualization at $20 \mathrm{kV}$ acceleration voltage. Pure elemental $\mathrm{Co}$ and $\mathrm{a} \mathrm{Bi}_{50} \mathrm{Rh}_{50}$ standard were applied for energy and intensity calibration. To minimize statistical 


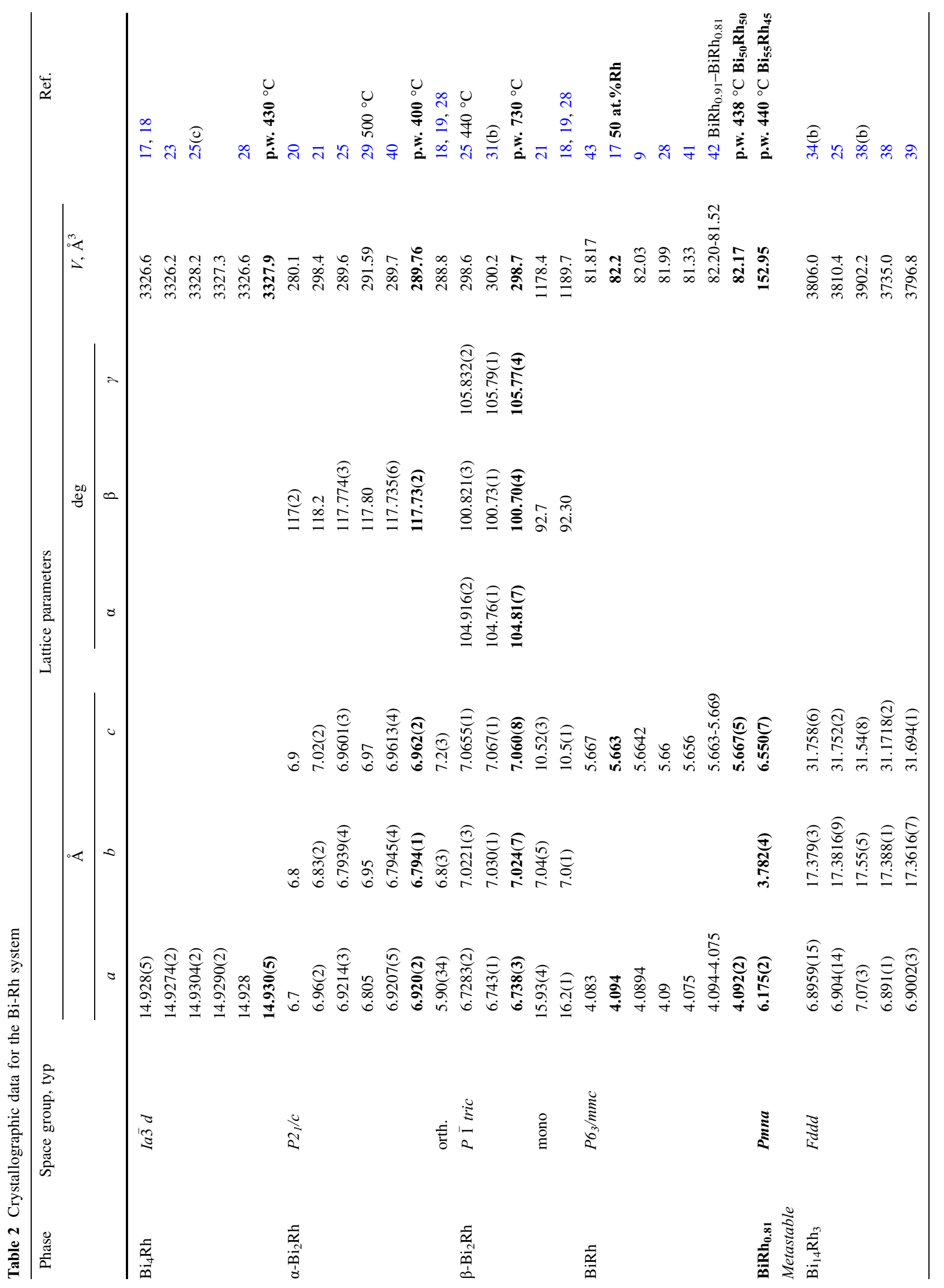




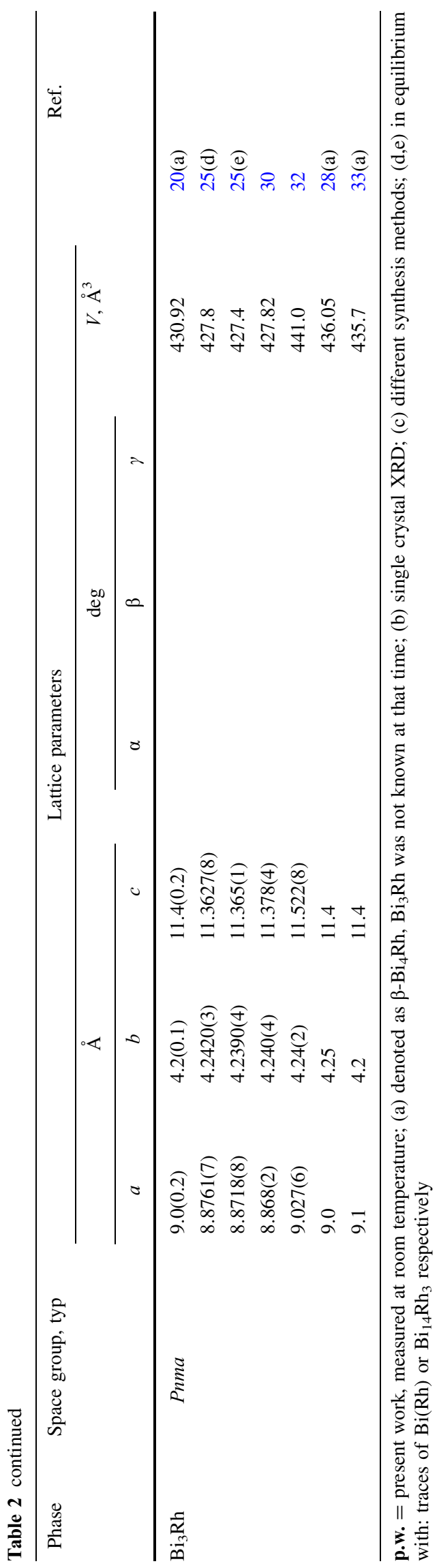

errors, the average phase composition was obtained from at least eight spot/area scans. A comparison between WDX and EDX measurements on the same samples showed a difference of $<0.8$ at.\% between the two techniques. On the other hand, the characteristic XRD radiation spectra of $\mathrm{Bi}$ and $\mathrm{Rh}$, especially the $\mathrm{Bi} \mathrm{M}$ line at $2.419 \mathrm{keV}$ and the $\mathrm{Rh} \mathrm{L}_{\alpha 1}$ line at $2.697 \mathrm{keV}$, are rather close, which makes it difficult to separate them in the measurement. This causes an inherent error of about 1-2 at.\% in the compositions derived from WDX/EDX measurements.

Differential thermal analyses (DTA) were performed on a DSC 404F1 Pegasus (Netzsch, Selb, Germany), applying evacuated silica glass crucibles $\left(\sim 10^{-3}\right.$ mbar $)$. The temperature program included two heating/cooling cycles at a rate of $5 \mathrm{~K} / \mathrm{min}$ starting from $200{ }^{\circ} \mathrm{C}$ up to about $30^{\circ}$ above the estimated liquidus temperature, not exceeding a maximum temperature of $1040{ }^{\circ} \mathrm{C}$. Two samples with 23 and 30 at.\% $\mathrm{Rh}$, respectively, were measured only up to $520{ }^{\circ} \mathrm{C}$. Temperature measurements were performed with type $\mathrm{S}(\mathrm{Pt} / \mathrm{PtRh})$ thermocouples, calibrated at the melting points of $\mathrm{Ag}, \mathrm{Au}, \mathrm{Bi}, \mathrm{Sb}$, and $\mathrm{Sn}$. $\mathrm{Zr}$ was used as reference material.

Invariant effects were evaluated from the peak onset, both on heating and cooling, liquidus effects were evaluated from the peak maximum on heating and from the peak onset on cooling. Generally, the effects evaluated in the first heating run of annealed samples were deemed most reliable.

\section{Results and Discussion}

Sample compositions, heat treatments and results of powder-XRD and EDX/WDX are summarized in Table 3. Table 4 contains the results of DTA measurements. A partial Bi-Rh phase diagram for compositions up to 70 at. $\% \mathrm{Rh}$ based on data obtained in this study and data from Ref 9 and 26, is presented in Fig. 1. Figure 2 and 3 show detail sections for the composition ranges 33.3-52 at.\% $\mathrm{Rh}$ (if $\mathrm{BiRh}_{0.81}$ is absent) and 19-33.3 at.\% $\mathrm{Rh}$ (if metastable $\mathrm{BiRh}_{3}$ is present). The Bi-rich part between 0 and 20 at.\% $\mathrm{Rh}$ was entirely taken from Okamoto. ${ }^{[26]}$ Figure 4(a), (b), (c), and (d) show SEM backscattered images for selected samples.

\subsection{Liquidus Curve}

The liquidus curve in Fig. 1 is based on DTA results of the quenched samples. Its shape, together with the corresponding invariant effects, indicates that the phases $\mathrm{BiRh}$ and $\beta-\mathrm{Bi}_{2} \mathrm{Rh}$ are formed by peritectic reactions, i.e., liquid with about 47 at.\% Rh reacts at $979 \pm 2{ }^{\circ} \mathrm{C}$ with $\mathrm{Rh}$ to form $\mathrm{BiRh}$, and liquid with about 29 at.\% $\mathrm{Rh}$ reacts at 


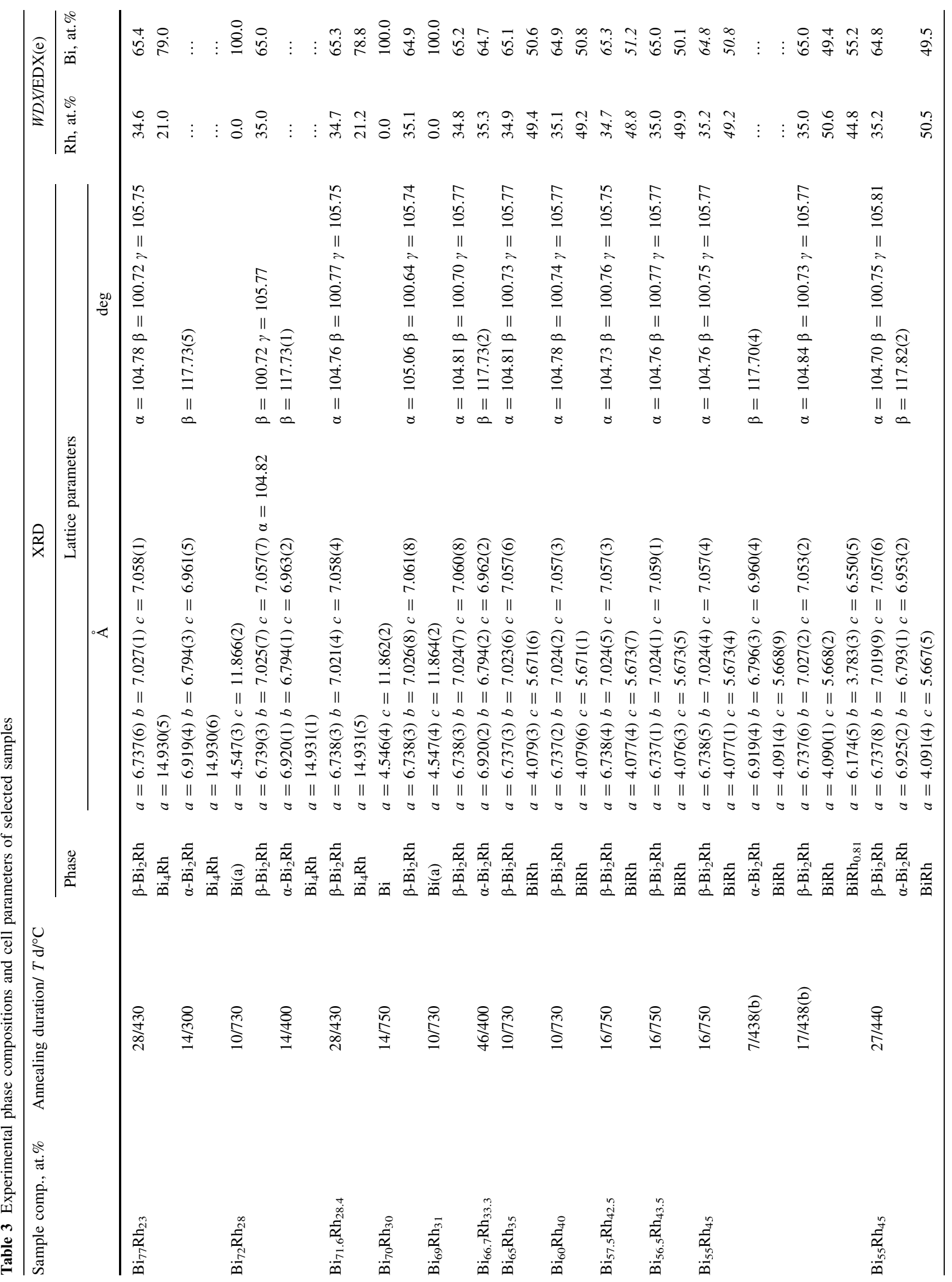




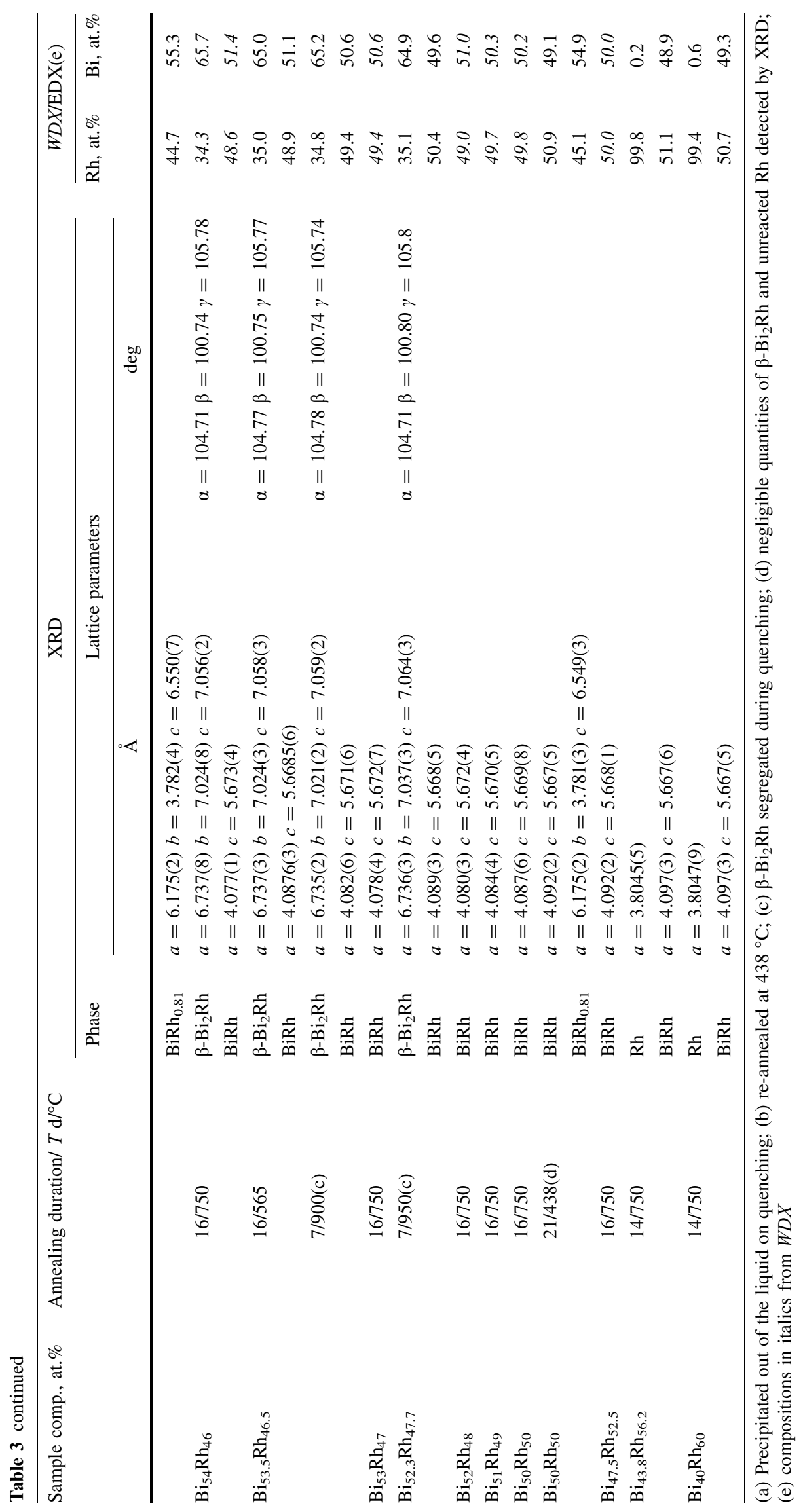


Table 4 Summary of measured thermal effects

\begin{tabular}{|c|c|c|c|c|c|}
\hline \multirow[t]{3}{*}{ Sample comp., at. $\%$} & \multirow[t]{3}{*}{ Annealing duration, $T \mathrm{~d} /{ }^{\circ} \mathrm{C}$} & \multicolumn{4}{|c|}{ Thermal analysis } \\
\hline & & \multicolumn{3}{|c|}{ Heating, ${ }^{\circ} \mathrm{C}$} & \multirow{2}{*}{$\begin{array}{c}\text { Cooling, }{ }^{\circ} \mathrm{C} \\
\text { Liquidus }\end{array}$} \\
\hline & & Invariant effects & Other effects & Liquidus & \\
\hline $\mathrm{Bi}_{77} \mathrm{Rh}_{23}$ & $28 / 430$ & $331 ; 448 ; 461$ & $\ldots$ & 734 & 697 \\
\hline $\mathrm{Bi}_{72} \mathrm{Rh}_{28}$ & $10 / 730$ & $329 ; 436 ; 453 ; 427 ; 460$ & $\ldots$ & 785 & 763 \\
\hline $\mathrm{Bi}_{70} \mathrm{Rh}_{30}$ & $14 / 750$ & $321 ; 430 ; 447 ; 423 ; 457$ & $\ldots$ & $\ldots$ & $\cdots$ \\
\hline $\mathrm{Bi}_{69} \mathrm{Rh}_{31}$ & $10 / 730$ & $433 ; 451 ; 423 ; 456 ; 785$ & $\cdots$ & 832 & 805 \\
\hline $\mathrm{Bi}_{66.7} \mathrm{Rh}_{33.3}$ & $46 / 400$ & $433 ; 429 ; 784$ & $\ldots$ & 863 & 855 \\
\hline $\mathrm{Bi}_{65} \mathrm{Rh}_{35}$ & $10 / 730$ & 448(a); 786 & $\cdots$ & 888 & 881 \\
\hline $\mathrm{Bi}_{60} \mathrm{Rh}_{40}$ & $10 / 730$ & $445(\mathrm{a}) ; 785$ & $\cdots$ & 932 & 927 \\
\hline $\mathrm{Bi}_{56.5} \mathrm{Rh}_{43.5}$ & $14 / 750$ & $450(a) ; 785$ & $\ldots$ & 961 & 941 \\
\hline $\mathrm{Bi}_{55} \mathrm{Rh}_{45}$ & $15 / 750$ & $446(\mathrm{a}) ; 785$ & $\ldots$ & 975 & 954 \\
\hline $\mathrm{Bi}_{54} \mathrm{Rh}_{46}$ & $15 / 750$ & $448(a) ; 785$ & $\ldots$ & 979 & 966 \\
\hline $\mathrm{Bi}_{53.5} \mathrm{Rh}_{46.5}$ & $14 / 565$ & $451(a) ; 785$ & $\ldots$ & 978 & 961 \\
\hline $\mathrm{Bi}_{53} \mathrm{Rh}_{47}$ & $15 / 750$ & 979 & 817 & 1016 & 970 \\
\hline $\mathrm{Bi}_{51} \mathrm{Rh}_{49}$ & $15 / 750$ & 977 & $\ldots$ & $\ldots$ & $\ldots$ \\
\hline $\mathrm{Bi}_{50} \mathrm{Rh}_{50}$ & $23 / 438$ & 978 & $\ldots$ & $\ldots$ & $\ldots$ \\
\hline $\mathrm{Bi}_{47.5} \mathrm{Rh}_{52.5}$ & $15 / 750$ & 979 & $\ldots$ & $\ldots$ & $\ldots$ \\
\hline $\mathrm{Bi}_{40} \mathrm{Rh}_{60}$ & $14 / 750$ & 980 & $\ldots$ & $\ldots$ & $\ldots$ \\
\hline
\end{tabular}

Italics: second heating; (a) metastable, only first heating, not appearing in second heating loop

Fig. 1 Bi-Rh phase diagram according to the present results without the metastable $\mathrm{Bi}_{3} \mathrm{Rh}$ phase; dashed lines are estimated. The Bi-rich part was taken from Okamoto. ${ }^{[26]}$ Circle, invariant thermal effects; triangle, liquidus on heating; inverted triangle, liquidus on cooling; cross, thermal effects related to phase boundaries; open diamond, phase boundary extrapolated from lattice parameter $a$ of $\mathrm{BiRh}$ phase as a function of Rh concentration (Fig. 7); filled diamond, values from Ross and Hume-

Rothery. ${ }^{[9]}$ The insert A shows a detail of the $\alpha-\mathrm{Bi}_{2} \mathrm{Rh} \rightleftharpoons \beta$ $\mathrm{Bi}_{2} \mathrm{Rh}$ region at 33.3 at.\% $\mathrm{Rh}$ in the case that metastable $\mathrm{Bi}_{3} \mathrm{Rh}$ is not present

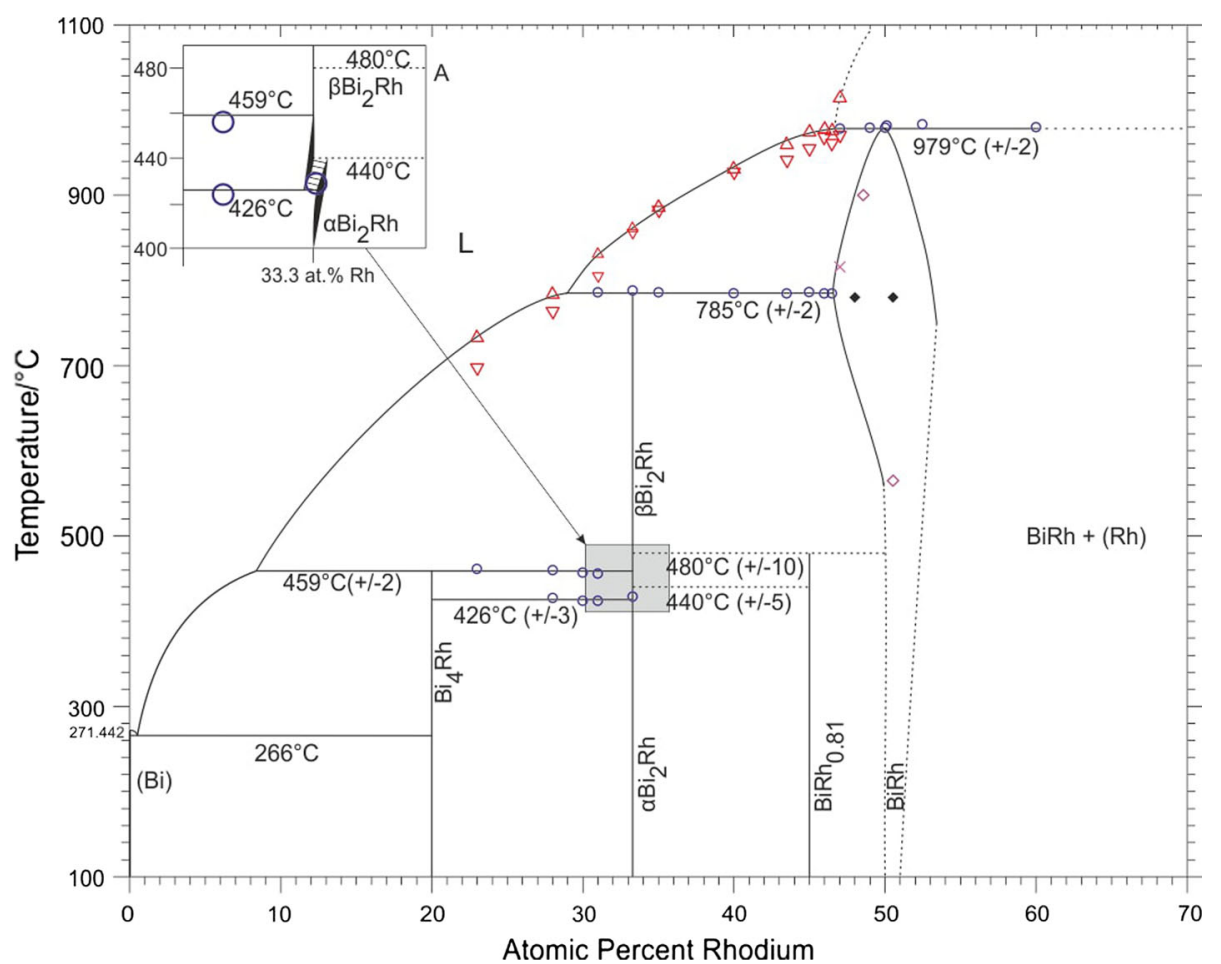

$785 \pm 2{ }^{\circ} \mathrm{C}$ with $\mathrm{BiRh}$ to form $\beta-\mathrm{Bi}_{2} \mathrm{Rh}$. These values are in good agreement with results of Ross and Hume-Rothery ${ }^{[9]}$ (46.0 at.\% Rh at $977^{\circ} \mathrm{C}$ for BiRh and 29.5 at.\% Rh at $780^{\circ}$ $\mathrm{C}$ for $\mathrm{Bi}_{2} \mathrm{Rh}$ ), based on results from cooling curves.
The shape of the liquidus curve at higher temperatures above the peritectic decomposition of BiRh could not be determined, because no signals were found except in the 


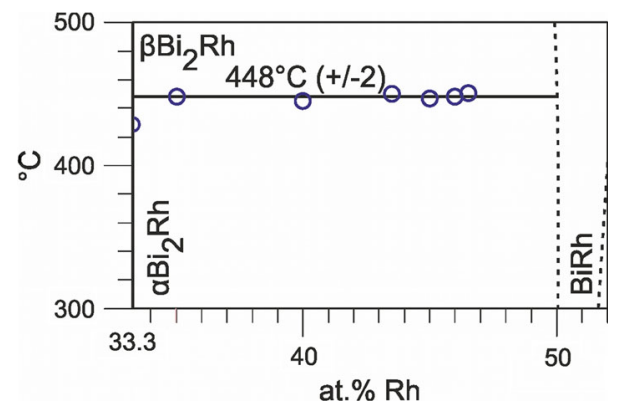

Fig. 2 Detail of Bi-Rh phase diagram between 33.3 and 52 at.\% Rh and $300-500{ }^{\circ} \mathrm{C}$, without $\mathrm{BiRh}_{0.81}$; dashed lines are estimated. Circle: invariant thermal effects. The $448 \pm 2{ }^{\circ} \mathrm{C}$ is the transition temperature of $\alpha-\mathrm{Bi}_{2} \mathrm{Rh} \rightleftharpoons \beta-\mathrm{Bi}_{2} \mathrm{Rh}$ if $\mathrm{BiRh}_{0.81}$ is not present. All thermal effects are listed in Table 4

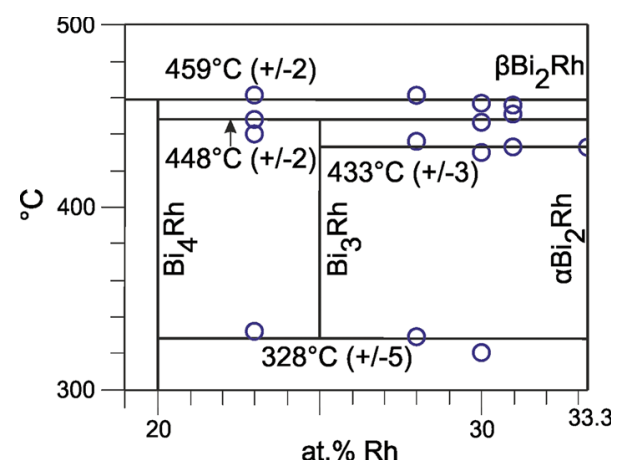

Fig. 3 Detail of Bi-Rh phase diagram between 19 and 33.3 at.\% Rh and $300-500{ }^{\circ} \mathrm{C}$. Circle, invariant thermal effects. If the metastable $\mathrm{Bi}_{3} \mathrm{Rh}$ is present the transition temperature of $\alpha-\mathrm{Bi}_{2}$ $\mathrm{Rh} \rightleftharpoons \beta-\mathrm{Bi}_{2} \mathrm{Rh}$ increases by a few degrees from $426 \pm 3$ to $433 \pm 3{ }^{\circ} \mathrm{C}$. All thermal effects are listed in Table 4

sample $\mathrm{Bi}_{53} \mathrm{Rh}_{47}\left(1016{ }^{\circ} \mathrm{C}\right)$. This indicates a very steep ascent to the melting point of $\mathrm{Rh}$.

\subsection{Composition Range 20-33.3 at.\% Rh}

The obtained results differ somewhat from the phase diagram assessed by Okamoto. ${ }^{[26]}$ In particular, no hint was found for the existence of the $\mathrm{Bi}_{3} \mathrm{Rh}$ phase in the XRD or EDX measurements of annealed samples. All samples in the investigated composition range showed exclusively $\mathrm{Bi}_{4} \mathrm{Rh}$ and $\alpha$ - or $\beta-\mathrm{Bi}_{2} \mathrm{Rh}$, independently of their annealing temperatures (Table 3).

DTA analyses of these samples show on first heating an extrapolated onset of the endothermic effect at $460 \pm 3{ }^{\circ} \mathrm{C}$ which represents the peritectic reaction $\left(\mathrm{L}+\beta-\mathrm{Bi}_{2}\right.$ $\mathrm{Rh} \rightleftharpoons \mathrm{Bi}_{4} \mathrm{Rh}$ ) temperature (Table 4). This value is slightly lower than the one reported by Weitzer et al. ${ }^{[25]}\left(466{ }^{\circ} \mathrm{C}\right.$ ) but in perfect agreement with the $460{ }^{\circ} \mathrm{C}$ assessed by Predel $^{[24]}$ Two thermal effects with average temperatures of $328 \pm 5$ and $448 \pm 2{ }^{\circ} \mathrm{C}$ were observed only in the corresponding second heating runs.
It was concluded that these correspond to the eutectoid and peritectoid reaction temperatures of (metastable) $\mathrm{Bi}_{3} \mathrm{Rh}$, described by Weitzer et al. ${ }^{[25]}$ into $\alpha-\mathrm{Bi}_{2} \mathrm{Rh}$ and $\mathrm{Bi}_{4} \mathrm{Rh}$ at $336{ }^{\circ} \mathrm{C}\left(\mathrm{Bi}_{3} \mathrm{Rh} \rightleftharpoons \mathrm{Bi}_{4} \mathrm{Rh}+\alpha-\mathrm{Bi}_{2} \mathrm{Rh}\right)$ and $433{ }^{\circ} \mathrm{C}\left(\mathrm{Bi}_{4} \mathrm{Rh}+\beta-\right.$ $\left.\mathrm{Bi}_{2} \mathrm{Rh} \rightleftharpoons \mathrm{Bi}_{3} \mathrm{Rh}\right)$. XRD measurements of samples after the DTA analyses did not show the $\mathrm{Bi}_{3} \mathrm{Rh}$ phase.

Combining the results of all analyses (Tables 3 and 4) suggests that $\mathrm{Bi}_{3} \mathrm{Rh}$ is actually a metastable phase which does not form in annealed samples, fully consistent with observations by Ross and Hume-Rothery ${ }^{[9]}$ who were likewise not able to detect the $\mathrm{Bi}_{3} \mathrm{Rh}$ phase. It is probably also in line with the report by Weitzer et al. ${ }^{[25]}$ who considered $\mathrm{Bi}_{3} \mathrm{Rh}$ to be a stable compound but found that it could only be obtained by annealing a mixture of $\mathrm{Bi}_{2} \mathrm{Rh}$ with a metastable phase, i.e., $\mathrm{Bi}_{14} \mathrm{Rh}_{3}$.

\subsection{The Phase $\mathrm{Bi}_{2} \mathrm{Rh}$}

WDX/EDX measurements of all samples containing $\beta$ $\mathrm{Bi}_{2} \mathrm{Rh}$ show an average composition of $34.9 \pm 0.5$ at. $\% \mathrm{Rh}$ independent of the annealing temperature. This value differs somewhat from the stoichiometric composition of 33.3 at.\% Rh. It is thought that this discrepancy is due to problems with the WDX/EDX measurements: the characteristic XRD radiation spectra of $\mathrm{Bi}$ and $\mathrm{Rh}$, especially the $\mathrm{Bi} \mathrm{M}$ line at $2.419 \mathrm{keV}$ and the $\mathrm{Rh} \mathrm{L}_{\alpha 1}$ line at $2.697 \mathrm{keV}$, are rather close, which makes it difficult to separate them in the measurement (see section 3.2). DTA results of samples containing the $\mathrm{Bi}_{2} \mathrm{Rh}$ phase show an invariant reaction at $785 \pm 2{ }^{\circ} \mathrm{C}$ which presents the peritectic reaction $\left(\mathrm{L}+\mathrm{BiRh} \rightleftharpoons \beta-\mathrm{Bi}_{2} \mathrm{Rh}\right)$. This temperature is in better agreement with the results by Ross and Hume-Rothery ${ }^{[9]}$ $\left(780{ }^{\circ} \mathrm{C}\right)$ and Kjekshus and Rakke ${ }^{[29]}\left(778 \pm 4{ }^{\circ} \mathrm{C}\right)$ than with those reported by Ref 16, 18, and 22 where it is somewhat lower.

Weitzer et al. ${ }^{[25]}$ indicated the transition of $\alpha$ - into $\beta$ $\mathrm{Bi}_{2} \mathrm{Rh}$ at $370{ }^{\circ} \mathrm{C}$ which could not be verified here, neither by DTA nor by powder XRD measurements of annealed samples. The data obtained in this study indicate a much more complex transition, its temperature being different below and above 33.3 at.\% $\mathrm{Rh}$, respectively, and also depending on the presence or absence of metastable $\mathrm{Bi}_{3} \mathrm{Rh}$ or stable $\mathrm{BiRh}_{0.81}$ phase.

XRD analysis of a sample with the stoichiometric composition $\mathrm{Bi}_{66.7} \mathrm{Rh}_{33.3}$, annealed for 46 days at $400{ }^{\circ} \mathrm{C}$, shows only $\alpha-\mathrm{Bi}_{2} \mathrm{Rh}$ (Fig. 5, bottom). A sample with 35 at. $\% \mathrm{Rh}$, quenched from $730{ }^{\circ} \mathrm{C}$, showed originally $\beta-\mathrm{Bi}_{2} \mathrm{Rh}$ and BiRh (Fig. 6, bottom); this sample was then subjected to high temperature XRD. On heating, the phase $\alpha-\mathrm{Bi}_{2} \mathrm{Rh}$ appears at $250{ }^{\circ} \mathrm{C}$ and disappears between 400 and $450{ }^{\circ} \mathrm{C}$ indicating a transition $\alpha-\mathrm{Bi}_{2} \mathrm{Rh} \rightleftharpoons \beta-\mathrm{Bi}_{2} \mathrm{Rh}$ below $450{ }^{\circ} \mathrm{C}$ on the Rh-rich side. Unfortunately, $\mathrm{Bi}_{2} \mathrm{Rh}$ starts to decompose above $500{ }^{\circ} \mathrm{C}$ due to the evaporation of $\mathrm{Bi}$ in 


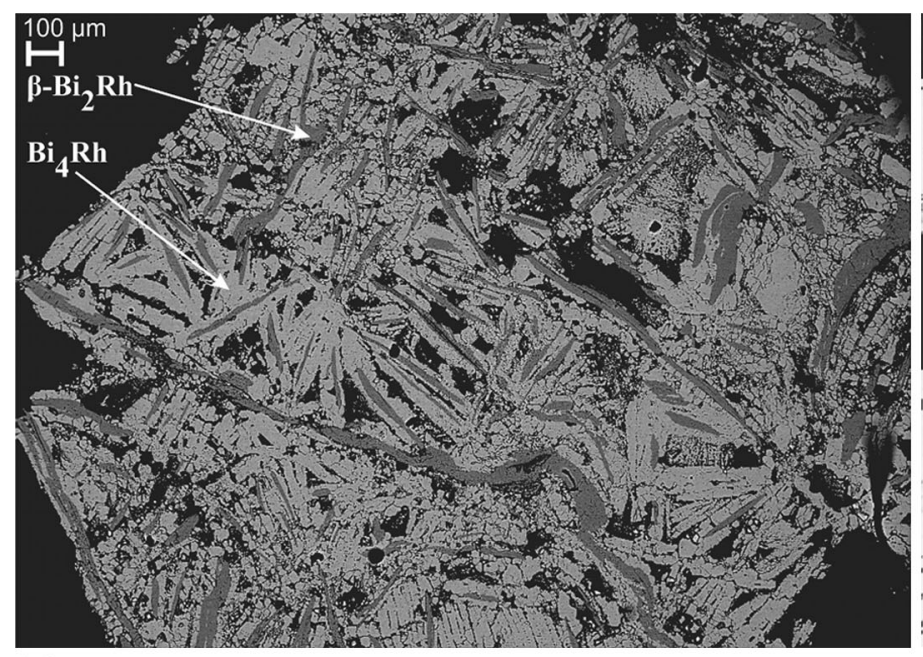

(a)

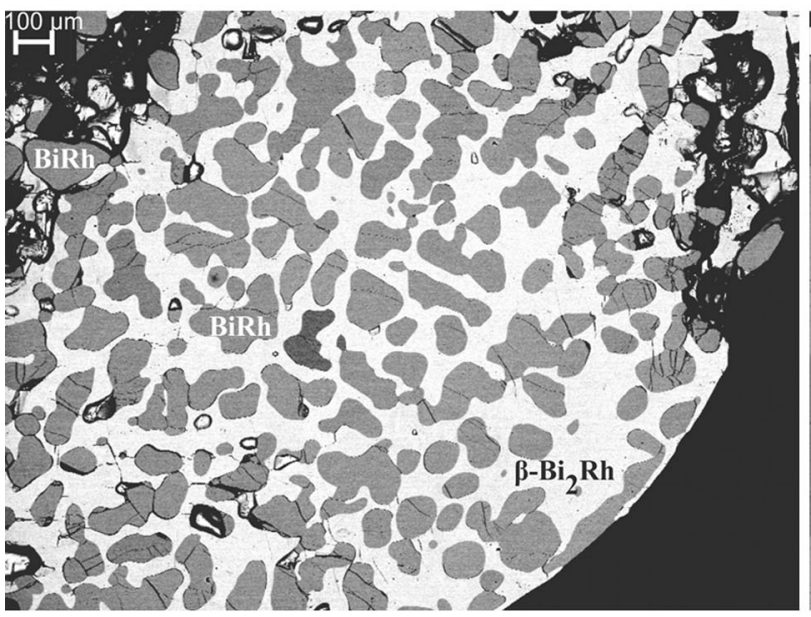

(c)

Fig. 4 SEM backscattered electron images of selected samples (black structures are either holes or cracks caused by sample preparation). (a) $\mathrm{Bi}_{71.6} \mathrm{Rh}_{28.4}$ annealed at $430{ }^{\circ} \mathrm{C}$, shows $\beta-\mathrm{Bi}_{2} \mathrm{Rh}$ phase surrounded by $\mathrm{Bi}_{4} \mathrm{Rh}$ matrix. (b) $\mathrm{Bi}_{43.8} \mathrm{Rh}_{56.2}$ annealed at $750{ }^{\circ} \mathrm{C}$, shows small

the evacuated high-temperature $\mathrm{x}$-ray chamber and disappears completely around $550{ }^{\circ} \mathrm{C}$, leaving only the $\mathrm{BiRh}$ phase.

The obtained XRD results are in good agreement with DTA data, which show in all samples with Rh contents $\geq 35$ at.\%, independently of the annealing parameters, an invariant effect at $448 \pm 2{ }^{\circ} \mathrm{C}$ (Table 4) if the new phase $\mathrm{BiRh}_{0.81}$ is not present. Quenching experiments indicate that this transition temperature is approximately $440 \pm 5^{\circ}$ $\mathrm{C}$ if the $\mathrm{BiRh}_{0.81}$ phase is present (Table 3).

The $\alpha \rightleftharpoons \beta$ transition temperature in the composition range below 33.3 at.\% $\mathrm{Rh}$ is $426 \pm 3$ or $433 \pm 3{ }^{\circ} \mathrm{C}$, depending on the absence or presence of the metastable $\mathrm{Bi}_{3} \mathrm{Rh}$ phase. XRD investigations of samples with 23 (Fig. 5, top) and 28.4 at.\% Rh, annealed at $430{ }^{\circ} \mathrm{C}$, (Table 3) reveal the $\beta$ modification of $\mathrm{Bi}_{2} \mathrm{Rh}$, the sample

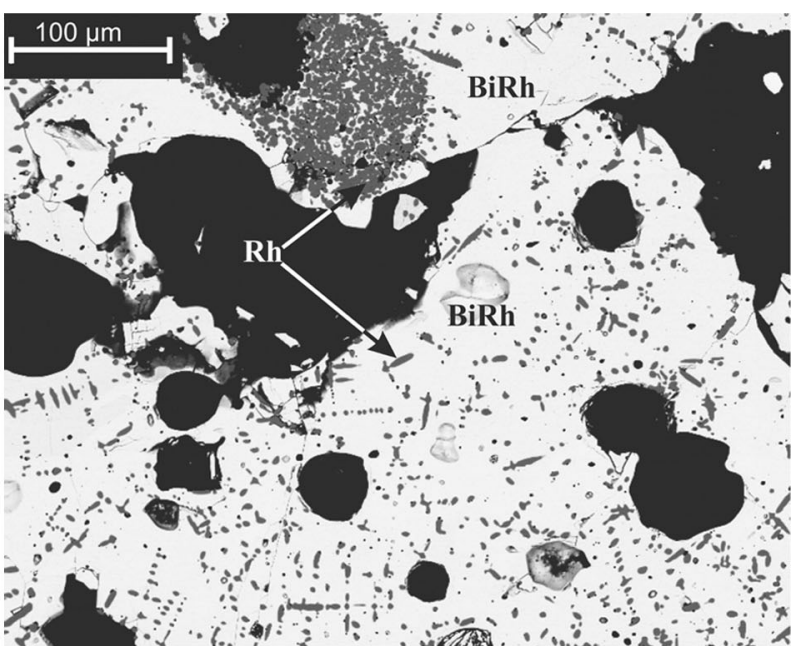

(b)

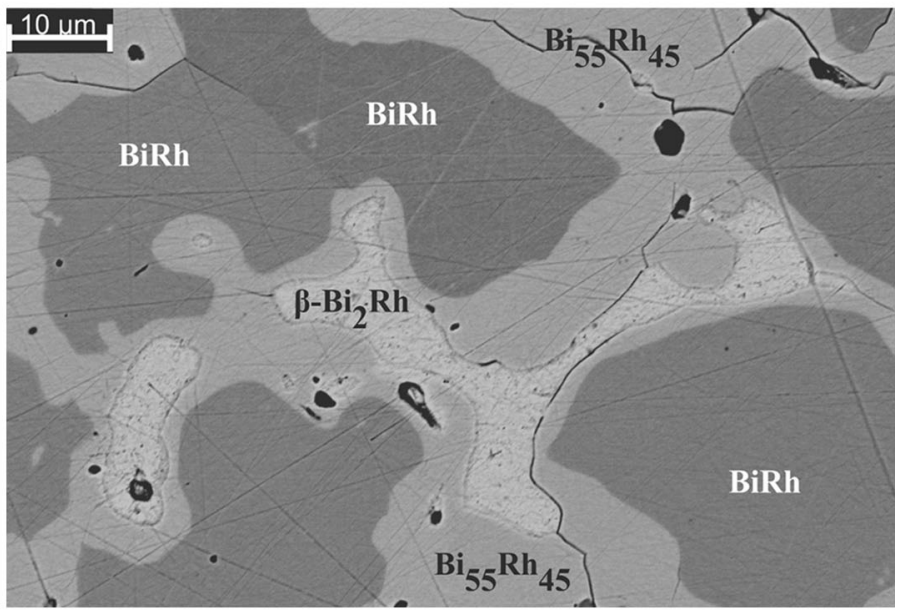

(d)

spots of $\mathrm{Rh}$ and $\mathrm{BiRh}$ phase. (c) $\mathrm{Bi}_{57.5} \mathrm{Rh}_{42.5}$ annealed at $750{ }^{\circ} \mathrm{C}$, shows $\mathrm{BiRh}$ and $\beta-\mathrm{Bi}_{2} \mathrm{Rh}$ phases. (d) $\mathrm{Bi}_{55} \mathrm{Rh}_{45}$ annealed at $440{ }^{\circ} \mathrm{C}$ shows $\mathrm{BiRh}, \beta-\mathrm{Bi}_{2} \mathrm{Rh}, \mathrm{BiRh}_{0.81}\left(\mathrm{Bi}_{55} \mathrm{Rh}_{45}\right)$ phases

with 28 at. \% Rh, annealed at $400{ }^{\circ} \mathrm{C}$, showed the $\alpha$ modification. These XRD results are in good agreement with DTA data, which show for all samples, independent of the annealing temperature, thermal arrests between 423 and $427^{\circ} \mathrm{C}$ (Table 4). They also agree with values of Kuz'min and Zhuravlev ${ }^{[21]}\left(420{ }^{\circ} \mathrm{C}\right.$, DTA), Ross and Hume-Rothery ${ }^{[9,23]}\left(430,425{ }^{\circ} \mathrm{C}\right.$, high temperature XRD), Kjekshus and Rakke ${ }^{[29]}$ (425 $\pm 3{ }^{\circ} \mathrm{C}$, DTA and quenching experiments) and Fjellvag and Furuseth ${ }^{[30]}\left(427 \pm 10^{\circ} \mathrm{C}\right.$, high temperature $\mathrm{XRD}$ ).

It is concluded that this difference in the $\alpha \rightleftharpoons \beta$ transition temperature for compositions below and above 33.3 at.\% $\mathrm{Rh}$ is caused by a eutectoid on the Bi-rich side $\left(\beta-\mathrm{Bi}_{2} \mathrm{Rh} \rightleftharpoons \mathrm{Bi}_{4} \mathrm{Rh}+\alpha-\mathrm{Bi}_{2} \mathrm{Rh}\right)$ and a peritectoid on the Rh-rich side $\left(\alpha-\mathrm{Bi}_{2} \mathrm{Rh} \rightleftharpoons \beta-\mathrm{Bi}_{2} \mathrm{Rh}+\mathrm{BiRh} / \mathrm{BiRh}_{0.81}\right)$ as indicated in the inset in Fig. 1. 


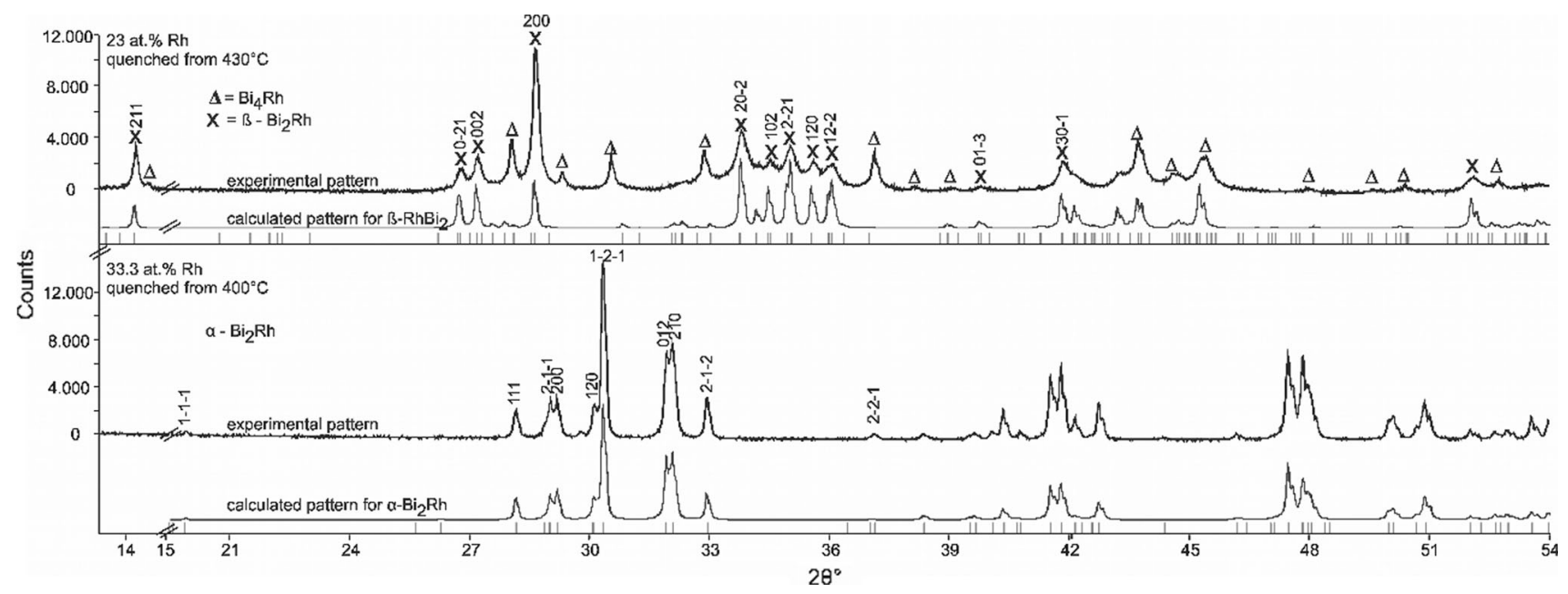

Fig. 5 Powder XRD pattern of a sample with 23 at.\% Rh quenched from $430{ }^{\circ} \mathrm{C}$ (top), and 33.3 at. $\%$ Rh quenched from $400{ }^{\circ} \mathrm{C}$ (bottom). The experimental pattern of the sample (above) and the calculated contribution of $\alpha$-, and $\beta-\mathrm{Bi}_{2} \mathrm{Rh}$ (below) are shown for both forms. The Miller indices are given for the ten first occurring reflexes of
$\mathrm{Bi}_{2} \mathrm{Rh}$ based on the $\mathrm{Bi}_{2} \mathrm{Rh}$ structure given by Ref 31 and 40 . Both peaks at 29.8 and $40.02 \theta^{\circ}$ in the bottom pattern are not corresponding to any phase. Excluded range between 15 and $202 \theta^{\circ}$ does not show any reflexes

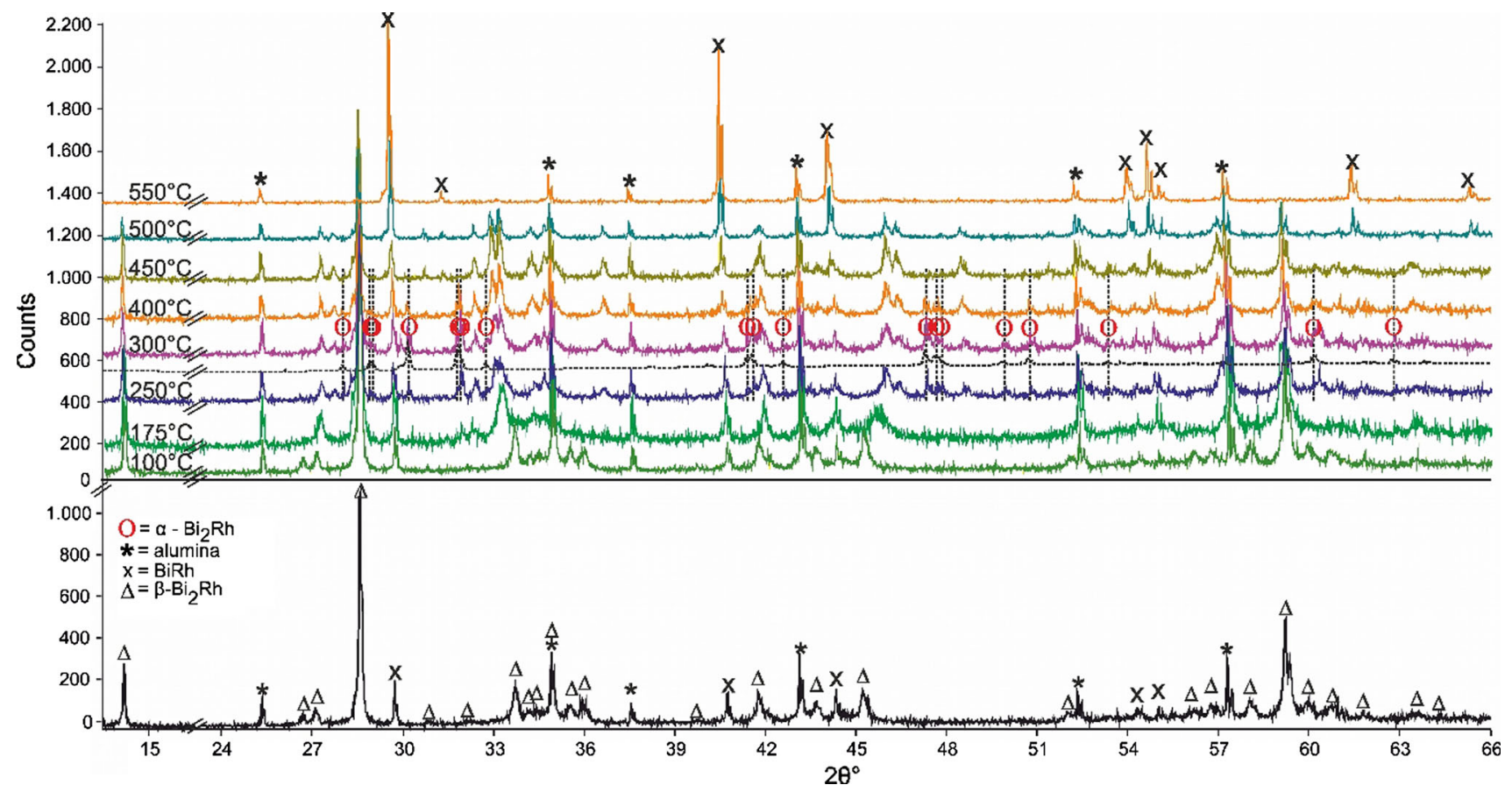

Fig. 6 Powder XRD pattern of a sample with 35 at.\% Rh quenched from $730{ }^{\circ} \mathrm{C}$ measured at ambient conditions (bottom) and at different temperatures (top). The dashed line between the 250 and $300{ }^{\circ} \mathrm{C}$ patterns shows the calculated XRD reflexes of $\alpha-\mathrm{Bi}_{2} \mathrm{Rh}$ at $300{ }^{\circ} \mathrm{C}$, marked with $\Theta$. For better illustration these reflexes are marked with

If the metastable $\mathrm{Bi}_{3} \mathrm{Rh}$ phase is present, DTA measurements of samples between 28 and 31 at.\% Rh show, independent of the annealing parameters, an invariant effect at $433 \pm 3{ }^{\circ} \mathrm{C}$ for the $\alpha \rightleftharpoons \beta$ transition (Table 4). But once again it must be pointed out that metastable $\mathrm{Bi}_{3-}$ $\mathrm{Rh}$ only occurs in second heating loops. A graphical vertical lines. The refinement is based on the structures given by Ref 9, 31, and 40. Peaks marked with * correspond to alumina sample carrier. Excluded range between 15 and $242 \theta^{\circ}$ does not show any reflexes

presentation of the reported values is given in Fig. 1 to 3 . The average transition temperature of $433 \pm 3{ }^{\circ} \mathrm{C}$ $\left(<33.3\right.$ at.\% Rh) corresponds to the value of $433^{\circ} \mathrm{C}$, which Weitzer et al. ${ }^{[25]}$ reported for the peritectoid decomposition of the $\mathrm{Bi}_{3} \mathrm{Rh}$ phase. 

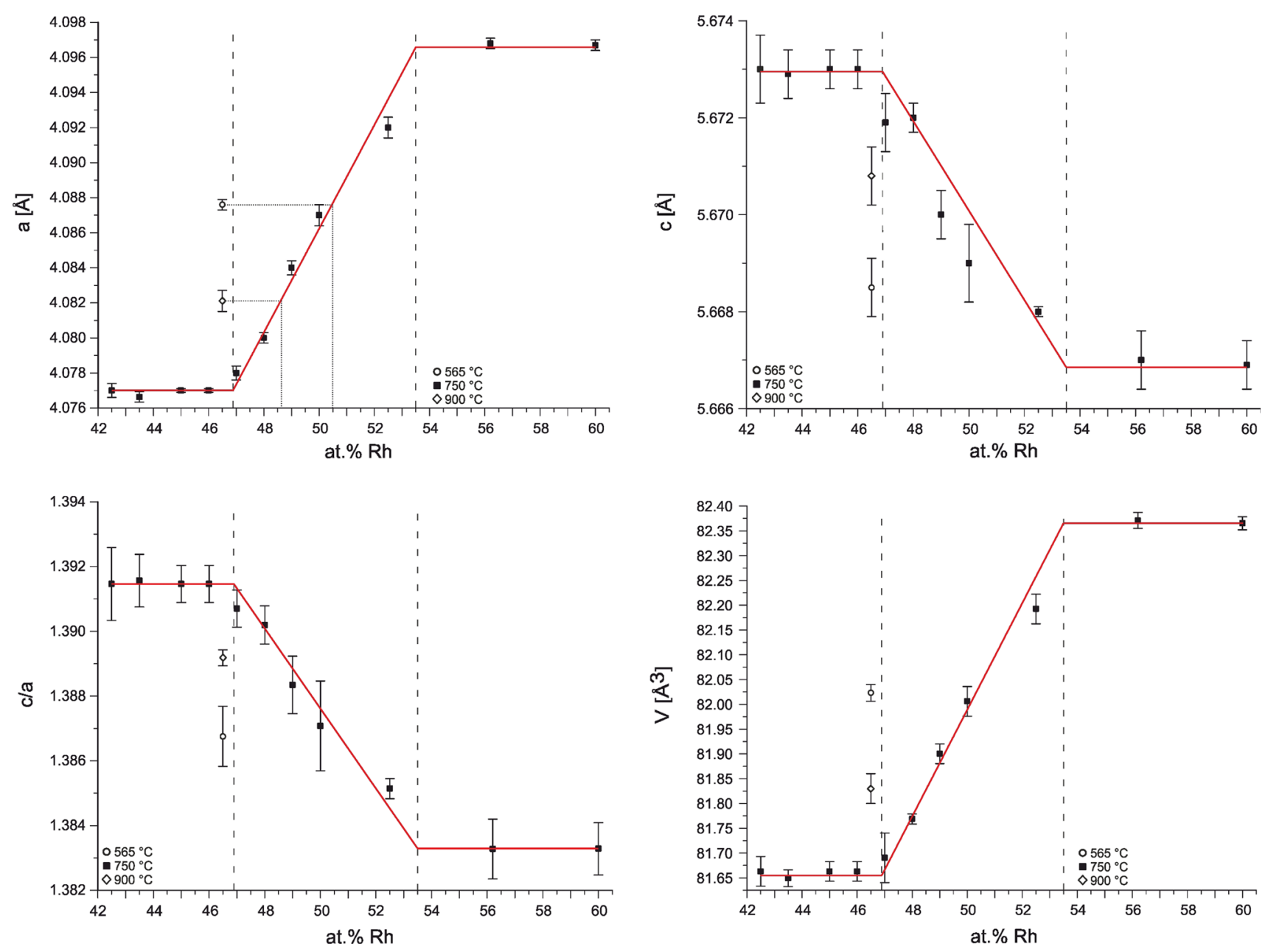

Fig. 7 Lattice parameters $a, c, c / a, V$ of BiRh as a function of Rh concentration. The dashed lines indicate the proposed phase boundaries at $750^{\circ}$ C

\subsection{The Phase BiRh}

The obtained homogeneity range of the phase BiRh differs from data reported in the literature ${ }^{[9,17]}$ as well as does the temperature of the peritectic. ${ }^{[16,20,26]}$

In particular, DTA results of samples between 47 and 60 at. $\% \mathrm{Rh}$ show an invariant reaction at $979 \pm 2{ }^{\circ} \mathrm{C}$ which is the peritectic decomposition temperature of BiRh. This value conforms to the $977{ }^{\circ} \mathrm{C}$ reported by Ross and HumeRothery ${ }^{[9]}$ but is $20{ }^{\circ} \mathrm{C}$ lower than assessed by Okamoto. ${ }^{[26]}$ Results on the homogeneity range of BiRh are somewhat contradictory: WDX/EDX results of samples in the adjacent two-phase fields, annealed at $750{ }^{\circ} \mathrm{C}$ seem to indicate a rather narrow stability range for $\mathrm{BiRh}$ between about 49.8 and 50.9 at.\% Rh. These values are in contrast to powder XRD investigations of samples between 47 and 52.5 at.\% $\mathrm{Rh}$ which show only $\mathrm{BiRh}$ and no second phase. As described in section 4.3, the characteristic XRD radiation spectra of $\mathrm{Bi}$ and $\mathrm{Rh}$ are rather close, which makes it difficult to separate them in the measurement. Therefore, the
EDX/WDX values may show unusually high errors and the homogeneity range of $\mathrm{BiRh}$, as it is shown in Fig. 1, is deduced from the lattice parameter measurements (Table 3 and Fig. 7).

The present results are in significant contrast to the values reported in the literature, particularly in Ref $16,17,24$, and 26. Of these, Glagoleva and Zhdanov ${ }^{[17]}$ annealed their samples at $800{ }^{\circ} \mathrm{C}$ but let them slowly cool down to room temperature instead of quenching; thus, their lattice parameters correspond obviously to some lower temperature. The results can be best compared to data by Ross and Hume-Rothery ${ }^{[9]}$ who determined the homogeneity range of $\mathrm{BiRh}$ at $780{ }^{\circ} \mathrm{C}$ as $48.0-50.6$ at. $\% \mathrm{Rh}$; this is in reasonable agreement with the present phase boundary on the Bi-rich side at $750{ }^{\circ} \mathrm{C}$, i.e., 46.9 at.\% $\mathrm{Rh}$, deduced from lattice parameter investigations. Extrapolating the lattice parameter $a$ of a sample with 46.5 at.\% Rh (annealed at different temperatures) to the plotted regression line (Fig. 7) indicates a pronounced retrograde solubility of $\mathrm{BiRh}$, resulting in a phase boundary of about 48 at. $\% \mathrm{Rh}$ at 
Table 5 Lattice parameters of $\mathrm{Bi}_{50} \mathrm{Rh}_{50}$ as a function of temperature, quenched from $438{ }^{\circ} \mathrm{C}$

\begin{tabular}{|c|c|c|c|c|c|c|c|c|c|}
\hline \multirow[t]{3}{*}{$T,{ }^{\circ} \mathrm{C}$} & \multicolumn{9}{|c|}{ Lattice parameters } \\
\hline & \multicolumn{5}{|c|}{$\mathrm{BiRh}_{0.81}$} & \multicolumn{4}{|c|}{$\mathrm{BiRh}$} \\
\hline & $a, \AA$ & $b, \AA$ & $c, \AA$ & $V, \AA^{3}$ & $c / b$ & $a, \AA$ & $c, \AA$ & $V, \AA^{3}$ & cla \\
\hline 25 & $6.175(3)$ & $3.781(4)$ & $6.549(5)$ & $152.94(2)$ & $1.732(1)$ & $4.092(5)$ & $5.667(1)$ & $82.21(3)$ & $1.384(2)$ \\
\hline 50 & $6.179(3)$ & $3.784(4)$ & $6.552(5)$ & $153.19(2)$ & $1.732(1)$ & $4.093(8)$ & $5.670(2)$ & $82.30(4)$ & $1.385(3)$ \\
\hline 75 & $6.182(3)$ & $3.785(4)$ & $6.555(5)$ & $153.39(2)$ & $1.732(1)$ & $4.095(7)$ & $5.673(1)$ & $82.40(4)$ & $1.385(2)$ \\
\hline 100 & $6.185(3)$ & $3.786(4)$ & $6.557(5)$ & $153.58(2)$ & $1.732(1)$ & $4.096(6)$ & $5.675(1)$ & $82.49(3)$ & $1.385(2)$ \\
\hline 125 & $6.187(3)$ & $3.787(5)$ & $6.559(5)$ & $153.74(2)$ & $1.732(2)$ & $4.097(7)$ & $5.678(1)$ & $82.57(3)$ & $1.386(2)$ \\
\hline 150 & $6.190(2)$ & $3.788(4)$ & $6.561(5)$ & $153.89(2)$ & $1.732(1)$ & $4.098(7)$ & $5.681(1)$ & $82.65(3)$ & $1.386(1)$ \\
\hline 175 & $6.192(2)$ & $3.789(4)$ & $6.563(5)$ & $154.02(2)$ & $1.732(1)$ & $4.099(7)$ & $5.683(1)$ & $82.71(3)$ & $1.386(2)$ \\
\hline 200 & $6.194(2)$ & $3.790(4)$ & $6.564(5)$ & $154.14(2)$ & $1.732(1)$ & $4.100(6)$ & $5.685(1)$ & $82.76(3)$ & $1.386(2)$ \\
\hline 225 & $6.196(2)$ & $3.791(4)$ & $6.566(5)$ & $154.27(2)$ & $1.732(1)$ & $4.100(6)$ & $5.686(1)$ & $82.82(3)$ & $1.387(2)$ \\
\hline 250 & $6.198(2)$ & $3.792(4)$ & $6.568(5)$ & $154.40(2)$ & $1.732(1)$ & $4.101(6)$ & $5.689(1)$ & $82.88(3)$ & $1.387(1)$ \\
\hline 275 & $6.200(2)$ & $3.793(3)$ & $6.569(5)$ & $154.53(2)$ & $1.731(1)$ & $4.102(6)$ & $5.691(1)$ & $82.94(3)$ & $1.387(2)$ \\
\hline 300 & $6.203(2)$ & $3.794(4)$ & $6.570(5)$ & $154.67(2)$ & $1.732(1)$ & $4.103(6)$ & $5.693(1)$ & $83.01(3)$ & $1.387(2)$ \\
\hline 325 & $6.205(2)$ & $3.795(4)$ & $6.573(5)$ & $154.83(2)$ & $1.732(1)$ & $4.104(6)$ & $5.695(1)$ & $83.08(3)$ & $1.388(2)$ \\
\hline 350 & $6.207(2)$ & $3.796(3)$ & $6.575(4)$ & $154.95(1)$ & $1.732(1)$ & $4.105(6)$ & $5.697(1)$ & $83.14(3)$ & $1.388(2)$ \\
\hline 375 & $6.209(2)$ & $3.797(3)$ & $6.578(3)$ & $155.11(2)$ & $1.733(1)$ & $4.106(6)$ & $5.699(1)$ & $83.22(3)$ & $1.388(2)$ \\
\hline 400 & $6.212(2)$ & $3.799(2)$ & $6.579(3)$ & $155.30(1)$ & $1.733(1)$ & $4.107(5)$ & $5.702(9)$ & $83.29(2)$ & $1.388(1)$ \\
\hline 425 & $6.214(2)$ & $3.800(3)$ & $6.582(4)$ & $155.47(1)$ & $1.732(1)$ & $4.107(5)$ & $5.705(9)$ & $83.37(2)$ & $1.389(1)$ \\
\hline 450 & $6.217(2)$ & $3.802(2)$ & $6.585(3)$ & $155.68(2)$ & $1.732(1)$ & $4.109(4)$ & $5.708(8)$ & $83.45(2)$ & $1.389(1)$ \\
\hline 475 & $6.220(5)$ & $3.804(7)$ & $6.587(9)$ & $155.89(4)$ & $1.731(2)$ & $4.110(3)$ & $5.710(7)$ & $83.54(2)$ & $1.389(1)$ \\
\hline 500 & - & - & - & - & - & $4.114(3)$ & $5.712(5)$ & $83.73(1)$ & $1.388(1)$ \\
\hline 525 & - & - & - & - & - & $4.118(3)$ & $5.713(5)$ & $83.91(1)$ & $1.387(1)$ \\
\hline 550 & - & - & - & - & - & $4.120(2)$ & $5.715(3)$ & $84.02(7)$ & $1.387(1)$ \\
\hline 575 & - & - & - & - & - & $4.121(2)$ & $5.717(4)$ & $84.09(1)$ & $1.387(1)$ \\
\hline 600 & - & - & - & - & - & $4.121(2)$ & $5.720(3)$ & $84.17(9)$ & $1.388(1)$ \\
\hline 625 & - & - & - & - & - & $4.122(4)$ & $5.723(8)$ & $84.23(2)$ & $1.388(1)$ \\
\hline 650 & - & - & - & - & - & $4.123(7)$ & $5.726(2)$ & $84.31(4)$ & $1.389(3)$ \\
\hline
\end{tabular}

900 and about 50.5 at.\% Rh at $565^{\circ} \mathrm{C}$. On the Rh-rich side, the lattice parameter measurements give a phase boundary of 53.5 at.\% $\mathrm{Rh}$ at $750{ }^{\circ} \mathrm{C}$ which points to a much wider homogeneity range of $\mathrm{BiMn}$ than reported in Ref 9

\subsection{The Phase BiRh $_{0.81}$}

SEM-EDX investigations of a sample with 50 at.\% $\mathrm{Rh}$, annealed for 21 days at $438^{\circ} \mathrm{C}$, showed, besides the known phases $\mathrm{BiRh}$ and $\mathrm{Bi}_{2} \mathrm{Rh}$, also a phase with a composition of $\mathrm{Bi}_{55} \mathrm{Rh}_{45}$ (54.9 at.\% $\mathrm{Bi}$ and 45.1 at.\% Rh). High temperature XRD measurements of the same sample (Table 5 and Fig. 8) showed that the reflexes of this phase disappear between 475 and $500{ }^{\circ} \mathrm{C}$.

Indexing of the unknown diffraction lines and subsequent refinement of the powder XRD pattern of a sample with the composition $\mathrm{Bi}_{55} \mathrm{Rh}_{45}$, annealed for 27 days at $440{ }^{\circ} \mathrm{C}$ (Table 3), indicates that the new phase is orthorhombic (Pnma) with the lattice parameters $a=6.1753(9) \AA, b=3.7817(1) \AA, c=6.5506(1) \AA$. Refinement was successful using the structural model for the MnP-type structure, which is closely related to the NiAs type of BiRh. The refined occupancy factor for $\mathrm{Rh}$ is $0.81(3)$, in excellent agreement with the phase composition of $\mathrm{Bi}_{55.3} \mathrm{Rh}_{44.7}$ determined by SEM-EDX. Therefore, this new phase was designated $\mathrm{BiRh}_{0.81}$. The refined atomic coordinates and structural parameters are given in Table 6 and Fig. 9 displays a $2 \theta$ segment of the powder XRD pattern between $26^{\circ}$ and $80^{\circ}$. Detailed structural information was deposited with Fachinformationszentrum Karlsruhe ${ }^{1}$ and can be obtained on quoting the depository number CSD 433459.

DTA measurements did not show any detectable signal between 475 and $500{ }^{\circ} \mathrm{C}$; thus, it is currently not possible to give a more exact value of the temperature of the peritectoid reaction $\left(\beta-\mathrm{Bi}_{2} \mathrm{Rh}+\mathrm{BiRh} \rightleftharpoons \mathrm{BiRh}_{0.81}\right)$ which is 


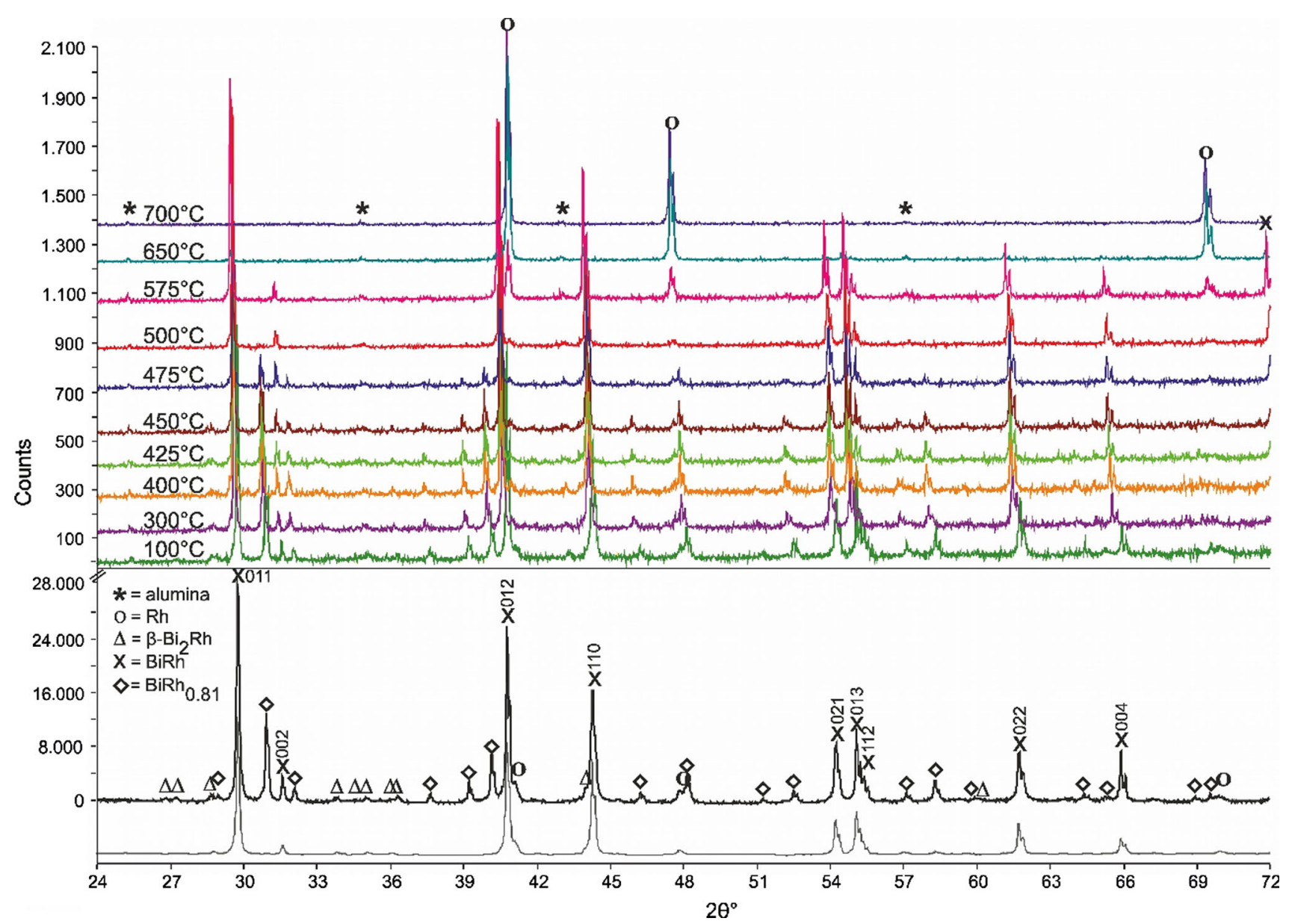

Fig. 8 Powder XRD patterns of a sample with 50 at.\% Rh quenched from $438{ }^{\circ} \mathrm{C}$ measured at ambient conditions (bottom), and at different temperatures (top). The experimental pattern of the sample (above) and the calculated contribution of $\mathrm{Rh}, \beta-\mathrm{Bi}_{2} \mathrm{Rh}, \mathrm{BiRh}$,

Table 6 Structural parameters for $\mathrm{BiRh}_{0.81}$, quenched from $440{ }^{\circ} \mathrm{C}$

\begin{tabular}{lccll}
\hline Atoms & Site & Atomic coordinate $(x, y, z)$ & SOF & $U_{\text {ISO }}$ \\
\hline Rh & 4 & $-0.0035(6), 0.25,0.1944(5)$ & $0.81(3)$ & $0.98(2)$ \\
$\mathrm{Bi}$ & 4 & $0.2019(2), 0.25,0.5947(2)$ & 1 & $0.98(2)$ \\
\hline
\end{tabular}

$U_{I S O}$ displacement parameter, SOF site occupancy factor

shown tentatively at $480{ }^{\circ} \mathrm{C}$ (Fig. 1). The reason for this might be a very small enthalpy effect due to the similar crystal structures of $\mathrm{BiRh}_{0.81}$ and $\mathrm{BiRh}$ in combination with a very slow kinetics (see below). A consequence of the presence of the $\mathrm{BiRh}_{0.81}$ phase is that the $\alpha \rightleftharpoons \beta$ transition temperature shifts on the Rh-rich side from $448 \pm 2{ }^{\circ} \mathrm{C}$ to a somewhat lower temperature. Annealing experiments with samples containing 45 at.\% Rh (see Table 3) show that it

\footnotetext{
${ }^{1}$ FIZ Karlsruhe, 76344 Eggenstein-Leopoldshafen, Germany, (fax: (49) 7247-808-666; e-mail: crysdata@ fiz.karlsruhe.de).
}

$\mathrm{BiRh}_{0.81}$ (below) are shown. The Miller indices are given for the $\mathrm{BiRh}$ reflexes. The refinement is based on the structures given by Ref 9, 31, and 44 . Peaks marked with $*$ correspond to the alumina sample carrier

must be around $440 \pm 5{ }^{\circ} \mathrm{C}$. Unfortunately, it is not possible to provide a more precise value of the transition temperature, as no DTA signal could be found in this temperature range.

The detection of $\mathrm{BiRh}, \beta-\mathrm{Bi}_{2} \mathrm{Rh}$ and of traces of $\alpha-\mathrm{Bi}_{2} \mathrm{Rh}$ in powder XRD and EDX measurements (Fig. 4d and Table 3) showed, that the annealing conditions $\left(440{ }^{\circ} \mathrm{C}\right.$, 27 days) were not sufficient to produce $B i R h_{0.81}$ as a single phase. Together with the fact that more than 2 weeks were necessary to form this compound, it indicates a very slow diffusion and/or formation kinetics. As noted above, the MnP-type $\left(\mathrm{BiRh}_{0.81}\right)$ and NiAs-type $(\mathrm{BiRh})$ structures are closely related and a transformation between them could even be of second order (see, e.g. Kjekshus and Pearson ${ }^{[27]}$ or Franzen et al. ${ }^{[36]}$ ). In the current case, however, the orthorhombic lattice parameters deviate considerably from those derived from the hexagonal parameters by cell transformation, pointing rather to a first-order transformation. This considerable distortion is probably due to the reduced occupation at the $\mathrm{Rh}$ site in $\mathrm{BiRh}_{0.81}$. 


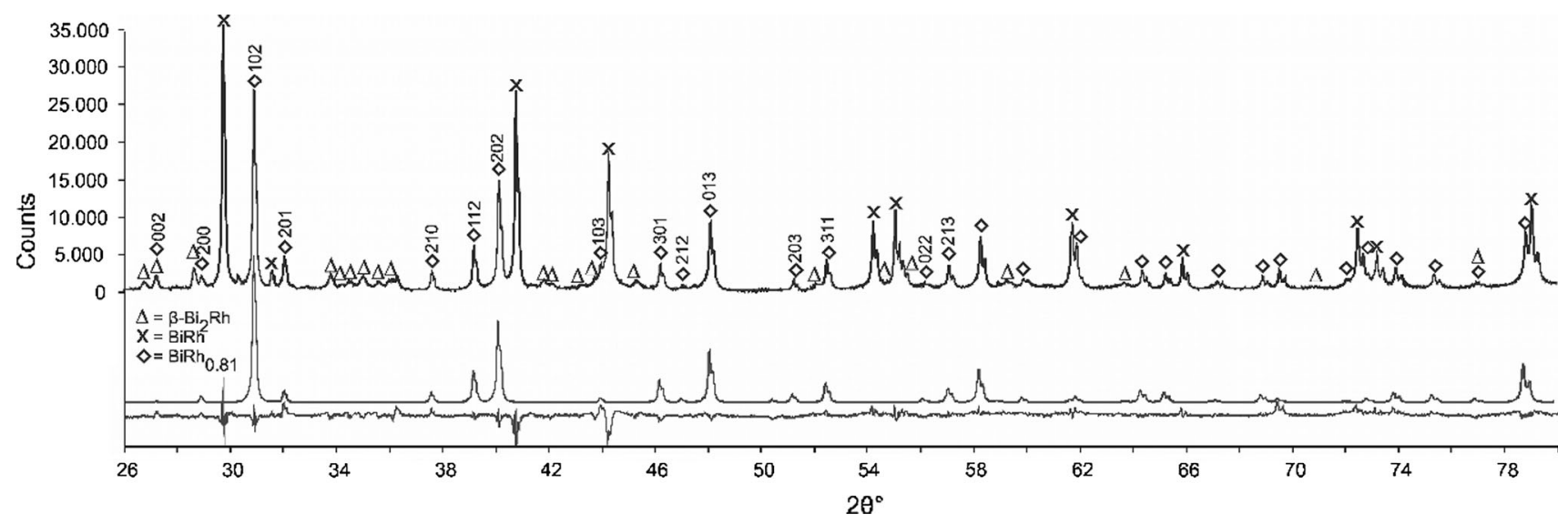

Fig. 9 Powder XRD pattern of a sample with 45 at.\% Rh quenched from $440{ }^{\circ} \mathrm{C}$ measured at ambient conditions. The pattern contains $\mathrm{BiRh}_{0.81}$ together with the phases $\mathrm{BiRh}$ and $\beta-\mathrm{Bi}_{2} \mathrm{Rh}$ as well as traces of $\alpha-\mathrm{Bi}_{2} \mathrm{Rh}$. The experimental pattern (above), the calculated pattern of $\mathrm{BiRh}_{0.81}$ (middle) and the difference curve (bottom) are shown.
The Miller indices are given for the first $15 \mathrm{BiRh}_{0.81}$ reflexes. The refinement is based on the structures given by Ref 9 and 31. One significant peak at $2 \theta=30.26^{\circ}$ and some other peaks not marked correspond to $\alpha-\mathrm{Bi}_{2} \mathrm{Rh}$. The $\alpha-\mathrm{Bi}_{2} \mathrm{Rh}$ phase is present with $<1$ wt. $\%$ in the sample
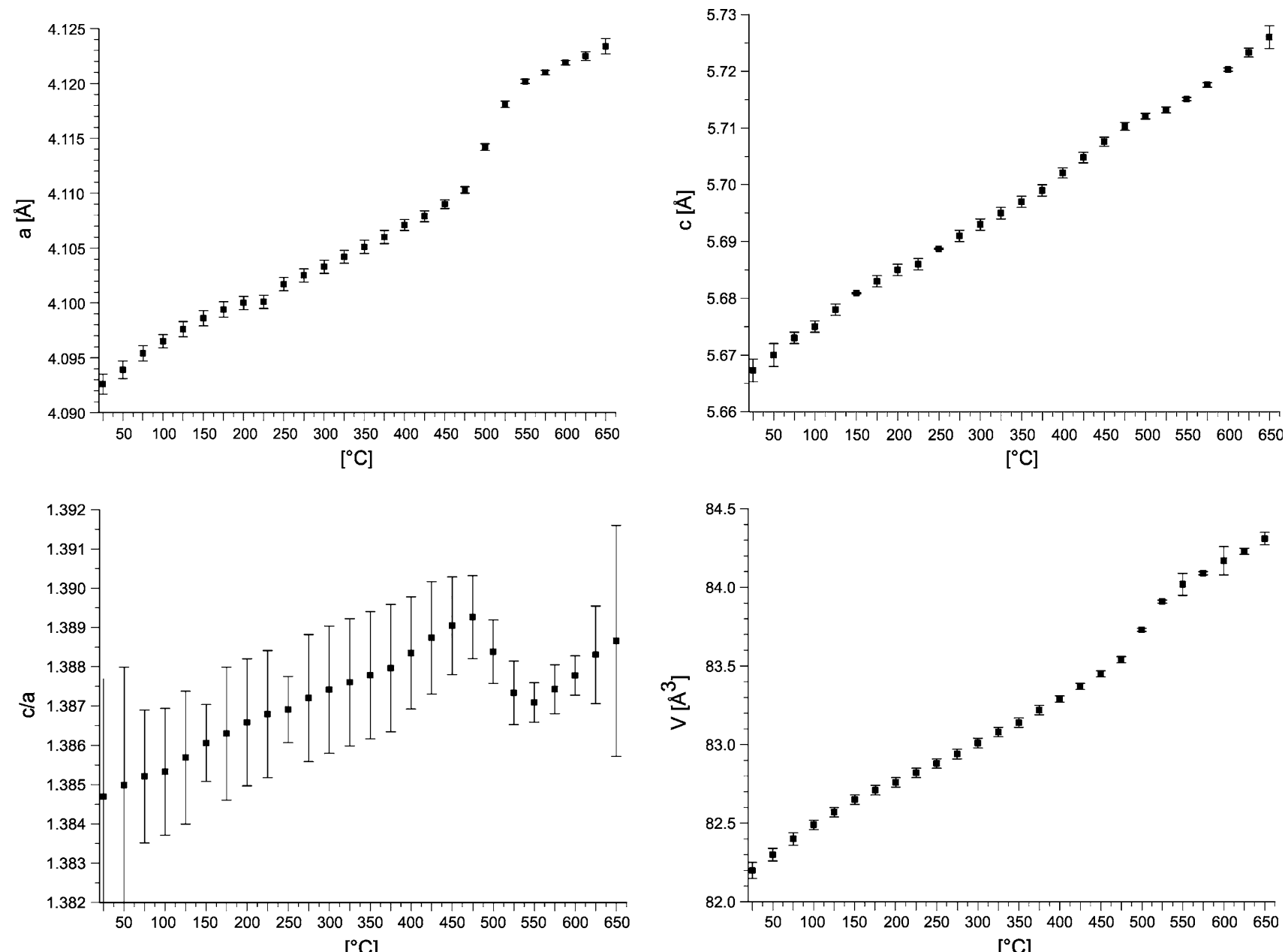

Fig. $10 \mathrm{BiRh}$ lattice parameters $a, c, c / a, V$ of a sample with 50 at.\% Rh, originally quenched from $438{ }^{\circ} \mathrm{C}$, as a function of temperature 

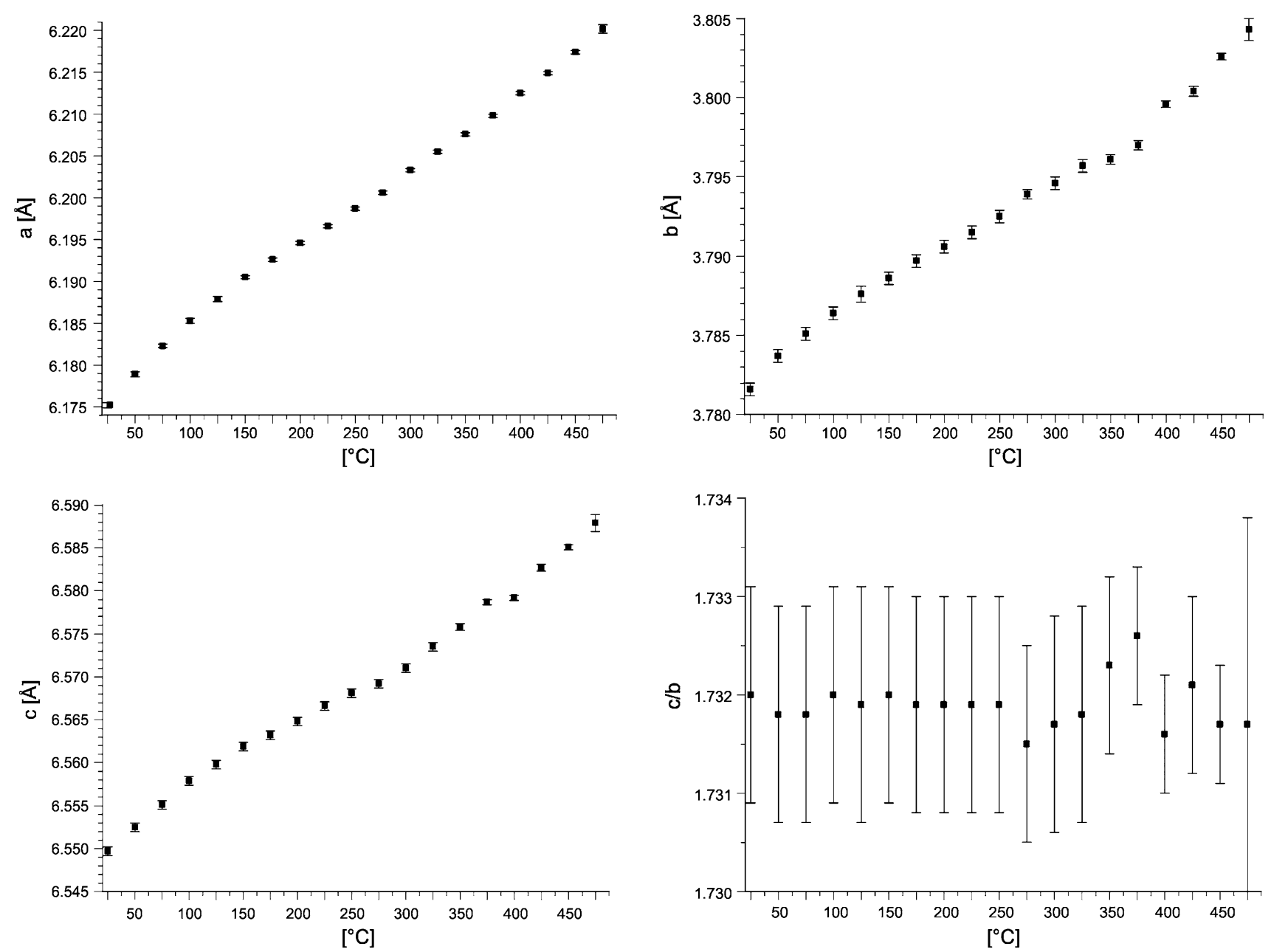

Fig. $11 \mathrm{BiRh}_{0.81}$ lattice parameters $a, b, c, c / b$, of a sample with 50 at.\% Rh, originally quenched from $438{ }^{\circ} \mathrm{C}$, as a function of temperature

\subsection{Lattice Parameters of the Phases BiRh and $\mathrm{BiRh}_{\mathbf{0 . 8 1}}$}

The unit cell parameters $a, c$, the ratio $c / a$ and the cell volume $V$ of the BiRh phase, measured on powders quenched from $750{ }^{\circ} \mathrm{C}$, are shown in Fig. 7. The lattice parameter $a$ increases whereas the lattice parameter $c$ decreases with increasing $\mathrm{Rh}$ content between 46.9 and 53.0 at.\% $\mathrm{Rh}$. The $c / a$ ratio decreases in the same direction and lies between 1.391(5) and 1.383(3) which is in the typical range of NiAs phases (but far away from the ratio $c / a=1.633$, typical for hexagonally close packing). From 42.5 to 46.9 at.\% $\mathrm{Rh}$ and from 53.5 to 60 at.\% $\mathrm{Rh}$ the unit cell parameters are constant within the error margins. From the lattice parameter $a$ of a sample with 46.5 at.\% Rh, annealed at 565 and $900{ }^{\circ} \mathrm{C}$, phase boundary values of 50.5 and 48.6 at.\% Rh were derived for $\mathrm{BiRh}$ at these temperatures, as indicated by dotted lines in Fig. 7. The corresponding data points are marked by diamonds in Fig. 1.
High temperature powder XRD measurements of a sample with 50 at.\% Rh, quenched from $438{ }^{\circ} \mathrm{C}$ (Table 5 and Fig. 8), yield slightly different lattice parameter values compared to data by Glagoleva and Zhdanov ${ }^{[17]}$ who analyzed a sample quenched from $780{ }^{\circ} \mathrm{C}$. As shown in Fig. 8, the BiRh phase starts to decompose above $475^{\circ} \mathrm{C}$ and disappears completely above $650{ }^{\circ} \mathrm{C}$. This is caused by evaporation of $\mathrm{Bi}$ from the $\mathrm{BiRh}$ phase into the dynamic vacuum of the high-temperature XRD chamber and leads to the appearance of $\mathrm{Rh}$ reflexes only. $\mathrm{Rh}$ reflexes in the pattern at ambient conditions are due to small amounts of non-reacted $\mathrm{Rh}$. As a consequence of the loss of the $\mathrm{BiRh}$ phase it was not possible to reproduce the significant increase of the lattice parameter $\mathrm{c}$ at $800{ }^{\circ} \mathrm{C}$ described by Ross and Hume-Rothery. ${ }^{[9]}$

With increasing temperature, the lattice parameters $a$ and $c$ and the volume of the unit cell $V$ increase (Table 5 and Fig. 10) for the BiRh phase. In contrast to lattice parameter $c$, which increases in the error margin linearly from 5.667(1) $\AA$ at room temperature to 5.726(2) $\AA$ at $650^{\circ}$ 
C, lattice parameter $a$ shows a steep increase between 475 and $550{ }^{\circ} \mathrm{C}$ [4.110(3)-4.120(2) $\AA$ ]. This step is probably related to the continuing decomposition of BiRh in the dynamic vacuum which becomes significant at this temperature. The loss of Bi shifts the composition of BiRh to the $\mathrm{Rh}$ rich side connected with an increase of lattice parameter $a$.

Similar to BiRh, the lattice parameters $a, b$, and $c$ of the $\mathrm{BiRh}_{0.81}$ phase (Table 5, Fig. 11) increase linearly with increasing temperature, too. Surprisingly, the $c / b$ ratio does not change and remains more or less constant within the error margin at $1.732 \AA$, which is not the case in most other MnP-type structure compounds (see, e.g., Selte and Kjekshus $^{[37]}$ ).

\section{Summary}

The Bi-Rh phase diagram in the range from 20 to 60 at. $\%$ $\mathrm{Rh}$ was reinvestigated by standard experimental methods, and a revised version is presented in Fig. 1. Most important result is the discovery of a new phase $\mathrm{BiRh}_{0.81}$ that is formed by a peritectoid reaction $\left(\beta-\mathrm{Bi}_{2-}\right.$ $\left.\mathrm{Rh}+\mathrm{BiRh} \rightleftharpoons \mathrm{BiRh}_{0.81}\right)$ at about $480{ }^{\circ} \mathrm{C}$. Apparently, its existence had been missed up to now due to its very sluggish formation.

The existence of the three phases $\mathrm{Bi}_{4} \mathrm{Rh}, \mathrm{Bi}_{2} \mathrm{Rh}$ (in two modifications depending on temperature), and $\mathrm{BiRh}$ could be confirmed. On the other hand, the phase $\mathrm{Bi}_{3} \mathrm{Rh}$, which had been included in the stable phase diagram by Okamoto, ${ }^{[26]}$ is thought to be actually metastable, as it could never be obtained in samples annealed in the corresponding temperature range. Based on the compositional variation of the lattice parameters, the homogeneity range of $\mathrm{BiRh}$ was established in the high-temperature range from about $600{ }^{\circ} \mathrm{C}$ up to its peritectic decomposition at $979{ }^{\circ} \mathrm{C}$.

Since the composition range below 20 at.\% $\mathrm{Rh}$ was not investigated in the present study, nothing can be said about the reportedly metastable compound $\mathrm{Bi}_{14} \mathrm{Rh}_{3}$.

The temperatures of many of the invariant reactions depend on the presence or absence of the two phases $\mathrm{Bi}_{3} \mathrm{Rh}$ and $\mathrm{BiRh}_{0.81}$. For example, the temperature of the peritectoid decomposition of $\alpha-\mathrm{Bi}_{2} \mathrm{Rh}$ differs by more than $10^{\circ}$ $\mathrm{C}$, depending on the presence or absence of the new phase $\mathrm{BiRh}_{0.81}$. Nevertheless, it is thought that the equilibrium diagram is correctly reflected by Fig. 1 .

Acknowledgments Open access funding provided by University of Vienna. Financial support of this work by the Austria Science Fund (FWF) through Project No. P 26023 is gratefully acknowledged. The authors also want to thank Dr. Stephan Puchegger from the Center for Nano Structure Research, University of Vienna, for support with the SEM/EDX measurements, Franz Kiraly for help with the WDX measurements, as well as Dr. Christian L. Lengauer for help with the high-temperature XRD measurements.

Open Access This article is distributed under the terms of the Creative Commons Attribution 4.0 International License (http://crea tivecommons.org/licenses/by/4.0/), which permits use, duplication, adaptation, distribution and reproduction in any medium or format, as long as you give appropriate credit to the original author(s) and the source, provide a link to the Creative Commons license and indicate if changes were made.

\section{References}

1. M.J. Kramer, R.W. McCallum, I.A. Anderson, and S. Constantinides, Prospects for Non-rare Earth Permanent Magnets for Traction Motors and Generators, JOM, 2012, 64(7), p 752-763

2. Y. Liu, J. Zhang, G. Jia, Y. Zhang, Z. Ren, X. Li, Ch Jing, S. Cao, and K. Deng, Magnetic Anisotropy Properties and Spin Reorientation for Textured Bi-Mn Alloys Fabricated by a Field-Inducing Technique, Phys. Rev. B, 2004, 70, p 184424-1-9

3. N.V. Rama Rao, A.M. Gabay, and G.C. Hadjipanayis, Anisotropic Fully Dense MnBi Permanent Magnet with High Energy Product and Coercivity at Elevated Temperatures, J. Phys. D Appl. Phys., 2013, 46, p 062001

4. C. Cui, J.P. Choi, G. Li, E. Polikarpov, J. Darsell, N. Overman, M. Olszta, D. Schreiber, M. Bowden, T. Droubay, M.J. Kramer, N.A. Zarkevich, L.L. Wang, D.D. Johnson, M. Marinescu, I. Takeuchi, Q.Z. Huang, H. Wu, H. Reeve, N.V. Vuong, and J.P. Liu, Thermal Stability of MnBi Magnetic Materials, J. Phys. Condens. Matter, 2014, 26, p 064212-1-4

5. J. Cui, J.-P. Choi, E. Polikarpov, M.E. Bowden, W. Xie, G. Li, Z. Nie, N. Zarkevich, M.J. Kramer, and D. Johnson, Effect of Composition and Heat Treatment on MnBi Magnetic Materials, Acta Mater, 2014, 79, p 374-381

6. Y.-Ch. Chen, G. Gregori, A. Leineweber, F. Qu, Ch.-Ch. Chen, T. Tietze, H. Kronmüller, G. Schütz, and E. Goering, Unique HighTemperature Performance of Highly Condensed MnBi Permanent Magnets, Scr. Mater., 2015, 107, p 131-135

7. M. Ellner, Über die kristallchemischen Parameter der Ni-, Cound Fe-haltigen phasen vom NiAs-Typ (Crystal Chemical Parameters of Nickel-, Cobalt- and Iron-Containing NickelArsenide (NiAs)-Type Phases), J. Less Common Met., 1976, 48, p 21-52, in German

8. B.T. Matthias, Transition Temperatures of Superconductors, Phys. Rev., 1953, 92(4), p 874-876

9. R.G. Ross and W. Hume-Rothery, On the Equilibrium Diagram of the System Bismuth-Rhodium, J. Less Common Met., 1962, 4, p 454-459

10. K. Lee, J.C. Suits, and G.B. Street, Stabilization on the High Temperature Phase of MnBi by the Addition of Rhodium or Ruthenium, Appl. Phys. Lett., 1975, 26(2), p 27-29

11. G.B. Street, J.C. Suits, and K. Lee, New Compounds in the Mn$\mathrm{X}$-Bi System Where $\mathrm{X}=\mathrm{Ni}, \mathrm{Cu}$, Rh or Pd, Solid State Chem., 1974, 14(1), p 33-36

12. V. Taufour, S. Thimmaiah, S. March, S. Saunders, K. Sun, T.N. Lamichhane, M.J. Kramer, S.L. Budko, and P.C. Canfield, Structural and Ferromagnetic Properties of an Orthorhombic Phase of MnBi Stabilized with Rh Addition, Phys. Rev. Appl., 2015, 4(1), p 01402119

13. J.C. Suits, Ferromagnetism in Bi- and Te- Substituted MnRh, IBM J. Res. Dev., 1975, 19(4), p 422-423

14. H. Rössler, Chem. Z. 24, 734 (1900), Original paper not available. Information taken from M. Hansen, Der Aufbau der 
Zweistofflegierungen: Eine kritische Zusammenfassung, 324-326 (1963) (in German)

15. L. Wöhler and L. Metz, Die Trennung der Platinmetalle (The Separation of the Platinum Metals), Z. Anorg. Chem., 1925, 149, p 309-310, in German

16. E.J. Rode, Izv. Inst. Plat. Drug. Blag. Met. 721 (1925), Original paper not available. Information taken from Gmelin Handbuch der anorg. Chem. Aufl. 8, Platin Teil A 5 (1974) (in German)

17. V.P. Glagoleva and G.S. Zhdanov, Structure of Superconductors III. X-ray Investigation of the Structure and Solubility of Components in BiRh, Zh.2, Eksp. Teor. Fiz., 1953, 25, p 248-254, in Russian

18. N.N. Zhuravlev and G.S. Zhdanov, The Structure of Superconductors VIII. X-ray and Metallographic Investigations of the System Bismuth-Rhodium, Sov. Phys. JETP, 1955, 1(1), p 91-99

19. N.E. Alekseevskii, G.S. Zhdanov, and N.N. Zhuravlev, The Problem of the Superconductivity of the Compounds $\mathrm{Bi}_{4} \mathrm{Rh}$ and $\mathrm{Bi}_{2} \mathrm{Rh}$, Sov. Phys. JETP, 1955, 1(1), p 99-102

20. G.S. Zhdanov, N.N. Zhuravlev, and R.N. Kuz'min, The BismuthRhodium System, Zhurn. Neorganich. Chim., 1958, 3, p 750-754, in Russian

21. R.N. Kuz'min and N.N. Zhuravlev, Determination of the Bi-Rh Phase Diagram with Greater Refinement, Kristallographie, 1961, 6, p 269-271, in Russian

22. R.N. Kuz'min, N.N. Zhuravlev, and G.S. Zhdanov, Thermal Analysis of the BiRh System, Zh. Neorg. Chim., 1963, 8, p 19061914, in Russian

23. R.G. Ross and W. Hume-Rothery, The Compound $\mathrm{Bi}_{4} \mathrm{Rh}, J$. Less Common Met., 1959, 1, p 304-308

24. B. Predel and Landolt-Börnstein, Group IV, Macroscopic and Technical Properties of Matter, Vol. 5: Phase Equilibria, Crystallographic and Thermodynamic Data of Binary Alloys, Subvol. H, Springer, Heidelberg, 1992, p 223-224

25. F. Weitzer, W. Schnelle, R.C. Gil, S. Hoffmann, R. Giedigkeit, and Y. Grin, Phase Relationship and Superconductivity in the BiRich Part of the Binary System Bi-Rh, Calphad, 2009, 33, p 2730

26. H.J. Okamoto, Bi-Rh (Bismuth-Rhodium), J. Phase Equilib. Diff., 2010, 31, p 204

27. A. Kjekshus and W.B. Pearson, Phases with the Nickel Arsenide and Closely Related Structures, Prog. Solid State Chem., 1964, 1, p 83-174

28. N.N. Zhuravlev and G.S. Zhdanov, X-ray Investigation of Compounds in the Systems Bi-Rh and Bi-Pd in Connection with the Study of Superconductivity, Bull. Acad. Sci. USSR, 1956, 20 (6), p 645-649, in Russian

29. A. Kjekshus and T. Rakke, High Temperature Studies of Marcasite and Arsenopyrite Type Compounds, Acta Chem. Scand. A, 1977, 31, p 517-529
30. H. Fjellvag and $\mathrm{S}$. Furuseth, Structural Properties of $\mathrm{Ni}_{1-t} \mathrm{Rh}_{t} \mathrm{Bi}_{3}$, J. Less Common Met., 1987, 128, p 177-183

31. M. Ruck, Kristallstruktur und Zwillingsbildung der intermetallischen Phase $\beta-\mathrm{Bi}_{2} \mathrm{Rh}$ (Crystal Structure and Twin Formation in the Intermetallic Phase $\left.\beta-\mathrm{Bi}_{2} \mathrm{Rh}\right)$, Acta Crystallogr. B, 1996, 52, p 605-609, in German

32. R.N. Kuz'min and G.S. Zhdanov, X-ray Analysis of the Superconducting Compound $\beta-\mathrm{Bi}_{3} \mathrm{Rh}$, Kristallographie, 1960, 5, p 869876 , in Russian

33. G.S. Zhdanov, N.N. Zhuravlev, R.N. Kuz'min, and A.I. Soklakov, A New Compound $\mathrm{Bi}_{3} \mathrm{Rh}$ in the System Bi-Rh Established by Means of X-Ray Diffraction, Kristallographie, 1958, 3, p 373 374

34. Q.F. Gu, G. Krauss, Y. Grin, and W. Streurer, Comparative HighPressure Study and Chemical Bonding Analysis of $\mathrm{Rh}_{3} \mathrm{Bi}_{14}$ and Isostructural $\mathrm{Rh}_{3} \mathrm{Bi}_{12} \mathrm{Br}_{2}$, J. Solid State Chem., 2007, 180(3), p 940-948

35. TOPAS 4.2 (Bruker AXS Inc., Karlsruhe, 2011)

36. H.F. Franzen, C. Hass, and F. Jellinek, Phase-Transitions Between NiAs-Type and MnP-Type Phases, Phys. Rev. B, 1974, 10(4), p 1248-1251

37. K. Selte and A. Kjekshus, On Phase Transitions Between the MnP and NiAs Type Structure, Acta Chem. Scand., 1973, 27, p 3195-3206

38. X. Zhang, H. Lei, and C. Petrovic, Superconducting State in the Metastable Binary Bismuthide $\mathrm{Rh}_{3} \mathrm{Bi}_{14}$ Single Crystals, Phys. Rev. B, 2012, 86, p 054502-1-5

39. M. Kaiser, B. Rasche, and M. Ruck, The Topochemical Pseudomorphosis of a Chloride into a Bismuthide, Angew. Chem. Int. Ed., 2014, 53, p 3254-3258

40. A. Kjekshus, On the Properties of Binary Compounds with the $\mathrm{CoSb}_{2}$ Typ Crystal Structure, Acta. Chem. Scand. A, 1971, 25(2), p 411-422

41. H. Pfisterer and K. Schubert, Neue Phasen Vom MnP(B31)-Typ (New Phases of MnP (B31) type), Z. Metallkd., 1950, 41, p 358367, in German

42. G.S. Zhdanov, Structure of Some Metallic Compounds of Bismuth, Trudy Inst. Krist. Akad. Nauk S.S.S.R., 1954, 10, p 99-116, in Russian

43. D. Köhler, M. Heise, A.I. Baranov, D. Geiger, M. Ruck, and M. Ambrüster, Synthesis of BiRh Nanoplates with Superior Catalytic Performance in the Semihydrogenation of Acetylene, Chem. Mater, 2012, 24, p 1639-1644

44. H.P. Singh, Determination of Thermal Expansion of Germanium, Rhodium and Iridium by X-rays, Acta. Cryst. A, 1968, 24, p 469470 